\title{
How Do Sell-Side Analysts Obtain P/E Multiples to Value Firms?
}

\author{
Yuan Yin (Corresponding Author) \\ Independent Scholar \\ E-mail: yuanyin78@gmail.com \\ Ken Peasnell \\ Professor of Accounting \\ Lancaster University Management School \\ Lancaster, LA1 4YX \\ United Kingdom \\ E-mail: k.peasnell@lancaster.ac.uk \\ Herbert G Hunt III \\ Professor of Accounting \\ Orfalea College of Business \\ California Polytechnic State University \\ San Luis Obispo, California 93407, United States \\ E-mail: hghunt@calpoly.edu
}

We thank the editor, Vivien Beattie, guest editors Mark Clatworthy and Edward Lee, and the two anonymous reviewers for their detailed comments and suggestions. We also thank Steve Young, Lisa Kutcher, and seminar participants at the 2013 American Accounting Association Annual Meeting and the 2011 American Accounting Association Western Region Meeting for their comments. All remaining errors are our own. 


\title{
How Do Sell-Side Analysts Obtain P/E Multiples to Value Firms?
}

\begin{abstract}
Previous studies of analysts' valuation methods show that sell-side analysts often rely on multiples-based relative valuation methods in deriving target price forecasts, predominantly earnings-based multiples. However, little is known about how analysts actually arrive at the earnings multiples that they apply in their valuations. Based on extant valuation theory, we analyse three benchmarks/reference points that analysts use to select these multiples using U.S. data. By mimicking analysts' relative valuation processes, we show that analysts tend to assign earnings multiple premiums (discounts) to those firms expected to have growth premiums (higher risk levels) relative to comparable firms. We provide evidence that analysts use firms' historical earnings multiples as benchmarks, and assign firms that are expected to have more (less) attractive fundamentals than they have had in the past earnings multiples that are at a premium (discount) relative to the average historical earnings multiples at which they traded. The forward P/E multiple for the broad U.S. market index signals the market's expectations about the growth prospects of the U.S. economy and future economic conditions and we also find that changes in this multiple affect analysts' choices of firm-specific earnings multiples.
\end{abstract}

Keywords: Relative valuation; analyst target P/E multiple; P/E multiple premium; growth and risk premiums; deviation from long-run average 


\section{Introduction}

Finance theory suggests that the value of a financial security is equal to the present value of the cash payoffs that an investor in that security expects to receive (Palepu and Healy 2013).

Accordingly, it is not surprising that standard valuation textbooks place considerable emphasis on present value models. It has been shown, however, that security analysts often use earnings multiples-based valuation methods in practice (Cascino et al. 2014). As key information intermediaries, sell-side analysts play an important role in promoting the efficient allocation of financial resources in capital markets, but we have limited knowledge regarding how analysts actually use the multiples method.

There are two main steps involved in applying the P/E multiple valuation method; the first involves choosing comparable firms and the second is to determine the earnings multiple for the firm under appraisal (the target firm). Graham and Dodd’s Security Analysis (1951, p. 507) states that 'The selection of an appropriate capitalization rate for expected earnings is just as important in the determination of a common stock's investment value as is a correct forecast of earnings. The two might be called the primary determinants of value'. However, despite its importance in the valuation process, the procedure of selecting an appropriate P/E multiple has received scant attention from researchers, who often simply adopt industry average multiples and focus on the selection of comparable firms (e.g., Bhojraj and Lee 2002, Liu et al. 2002, Nissim 2013).

Some progress has been made recently. Using hand-collected data from a small sample of analyst reports, Yin et al. (2014) show that the P/E multiples applied by analysts to value firms (i.e., analyst target $\mathrm{P} / \mathrm{E}$ multiple $)^{1}$ are positively associated with their near-term and long-term earnings growth forecasts and negatively associated with risk measures such as financial

\footnotetext{
${ }^{1}$ Following Yin et al. (2014), we use the term 'analyst target P/E multiple' to describe the forward P/E multiple which the analyst applies to value the target firm.
} 
leverage and book-to-market. However, since the sample in that study comprises only 321 research reports issued by six brokerage firms for 260 firms for less than two years (October 2010 to March 2012), it remains an open question as to whether the results are generalizable to the wider population of U.S. security analysts and firms or to a longer time frame. ${ }^{2}$ Most importantly, there are two questions essential for the understanding of analysts' multiples-based valuations that remain unexplored. First, how do analysts determine the magnitudes of the P/E multiples that they apply to value the firms they follow? While knowing that higher expected earnings growth (risks) warrants a higher (lower) earnings multiple (Yin et al. 2014) is important, ultimately analysts need to obtain the earnings multiples which they can then apply to their earnings forecasts. Second, what, if any, practical mechanisms and techniques do analysts employ to help obtain the appropriate P/E multiples for target firms? The present study attempts to seek answers to these two questions by examining three P/E multiple benchmarks (i.e., comparable firms' average, long-term historical average, and the market index’s multiple) which analysts appear to use in their valuations.

Ohlson and Juettner-Nauroth’s (2005) theoretical model suggests a positive (negative) relationship between a firm's intrinsic forward P/E multiple and the firm's near- and long-run expected earnings growth rates (the cost of capital). We follow Ohlson and Juettner-Nauroth (2005) and Graham and Dodd (1951) (hereinafter referred to for brevity as OJ and GD, respectively) in our identification of pertinent variables. Our research design includes using proxies for analyst target P/E multiples that we obtain through reverse engineering the analysts' valuation procedures, by dividing the target price forecast by the capitalized earnings per share

\footnotetext{
${ }^{2}$ An additional complication that study faced is that since the data item for long-term growth is not provided in a significant portion of the sample broker reports, the measure was estimated using only two or three years' (rather than the usual five years') forecasted income statements.
} 
estimate (provided that the $\mathrm{P} / \mathrm{E}$ multiple is the method used). This approach allows us to examine a large sample of U.S. firms across different economic sectors.

The results of our study show that by using the average P/E multiples of comparable firms as benchmarks, analysts appear to assign P/E multiple premiums to firms with growth premiums in the next fiscal year and in the medium-term, relative to comparable firms. They also seem to assign P/E multiple discounts to firms with higher levels of risk (e.g., earnings volatility, financial leverage). Firms with higher growth prospects relative to their long-run historical averages receive higher $\mathrm{P} / \mathrm{E}$ multiples from the analysts than the average historical P/E multiples at which they traded. The results show that firms with increased levels of financial risk and stock price volatility, compared to their long-run averages, are assigned lower $\mathrm{P} / \mathrm{E}$ multiples relative to the average P/E multiples at which they have historically traded. Finally, we find that revisions in analyst target P/E multiples are positively associated with changes in the forward P/E multiples of the Standard and Poor's 500 Composite Stock Index (S\&P 500 Index), suggesting that analysts' valuations incorporate information embedded in the market benchmark P/E multiples.

This study contributes to our knowledge of how analysts perform the P/E valuation method and, more generally, to the accounting-based valuation literature in several ways. First, we add to the literature by revealing how analysts use comparable firms' forward P/E multiples and target firm's historical P/E multiples as benchmarks to determine the magnitudes of earnings multiples that they apply to value firms. These findings stand in sharp contrast to the textbook prescription of universal application of an industry average. Second, to our knowledge, this is the first largesample study to empirically investigate how analysts select P/E multiples that are justified by firms' fundamentals by creating proxies for analyst target P/E multiples and industry coverages 
using analyst survey data. Third, our results provide additional support for the finding in Yin et al. (2014) that analysts apply the P/E multiple valuation method in ways that are consistent with the OJ theory that the P/E multiples are positively associated with the near-term and long-run growth rates in future earnings. While we also find that financial statement measures, earnings stability and financial leverage affect analysts’ choices of P/E multiples, the effect of high past

profitability and past growth appears to be rather limited. Fourth, we provide additional evidence on analysts' risk analyses in the context of their relative valuations. Fifth, this research is one of only a few studies (e.g., Bradshaw 2004; Yin et al. 2014) that shed light on analysts’ decision processes by examining the relationships among multiple analysts’ outputs. This study therefore adds to our knowledge of analysts' valuation activities, both by showing that what they do is not simply a result of applying ad hoc procedures but rather can be reconciled with what prior work suggests should be the relationship between stock valuations and accounting variables and the part played by their assessments of risk.

The remainder of the paper is organized as follows. The next section reviews related studies, Section 3 presents our hypotheses and Section 4 presents our empirical design. Sections 5 and 6 describe our sample and present empirical results. Section 7 presents additional empirical analysis. Section 8 reports results of sensitivity analyses and Section 9 presents concluding comments.

\section{Related research}

Over sixty years ago, GD suggested that equity investment decisions should be based on a formal appraisal of the value of the business following a thorough study of all available facts (e.g., earnings, assets, dividends, definite prospects). They suggest that the analyst should develop an 
estimate of the average expected earnings for the subsequent five to ten years (i.e., the earnings power). ${ }^{3}$ The value of the business can then be estimated by applying to the earnings estimate a capitalization rate/multiplier that takes account of expectations about the business's growth prospects in the longer run. They go on to identify two categories of determinants of the earnings multiple: one that includes easily measurable variables and another that includes non-measurable intangibles. The first category includes factors such as profitability, progress (e.g., past growth), earnings stability and financial strength, all of which can be determined by examining the firm's financial statements. The intangible factors are those that would be expected to influence, and probably control, the firm's long-run growth prospects including the nature and future prospects of the target firm's industry, the firm's relative standing in the industry, and the quality of the firm’s management team.

OJ show that under fairly general conditions the value of an equity security can be expressed as being equal to the capitalized one-year-ahead earnings per share plus the present value of capitalized abnormal earnings growth in all future periods:

$$
V_{0}^{E}=\frac{E P S_{1}}{r}+\sum_{t=1}^{\infty}\left[R^{-t}\left\{\frac{A E G_{t+1}}{r}\right\}\right]
$$

where: $V_{0}^{E}$ is the value of an equity security at date $t=0 ; r$ is the cost of equity capital; $R$ is the discount factor, equivalent to 1 plus the cost of capital, $r$; and $A E G_{t+1}=e p s_{t+1}-\left[e p s_{t}(1+r)-r \cdot d p s_{t}\right]$ is abnormal earnings growth, defined as the change in EPS adjusted for the cost of capital and dividends $\left(d p s_{\mathrm{t}}\right)$. To formalize growth in the equation,

\footnotetext{
${ }^{3}$ These ideas have played a part in research in the intervening years. For example, Beaver and Morse (1978) and Barker and Imam (2008) suggest that the quality of earnings per share used in P/E-based valuations is important and that transitory items should be excluded. Existing evidence suggests that analyst earnings forecasts exclude transitory elements and reflect their assessments of firms' sustainable future earnings (e.g., Bradshaw and Sloan 2002, Barker and Imam 2008).
} 
the authors introduce a measure of growth in expected EPS in period $t=2, g_{2}{ }^{4}$. Assuming $A E G$ grows at a constant compound rate of $(\gamma-1)$ after period $t=2$, OJ show that the intrinsic forward P/E multiple is dependent on a near-term growth rate in expected EPS, $g_{2}$, a long-run growth rate in abnormal earnings growth, $\gamma-1$, and the cost of capital, as follows: ${ }^{5,6}$

$$
\frac{V_{0}^{E}}{e p s_{1}}=\frac{1}{r} \times \frac{g_{2}-(\gamma-1)}{r-(\gamma-1)}
$$

Little empirical evidence exists on how analysts deal with risk in security analysis. At least two survey studies have reported that most analysts do not believe (or are at least not willing to admit that they believe) in the Efficient Market Hypothesis and the CAPM (Block 1999, Barker 1999b). These findings should not be surprising since, unlike investment texts, analysts do not assume the market is efficient (Penman 2013). Lui et al. (2007) suggest that analysts’ perception of risk is multidimensional. They show that risk ratings issued by Salomon Smith Barney (now known as Morgan Stanley Smith Barney) are associated with risk measures identified in the literature such as idiosyncratic risk, leverage, size and book-to-market risk proxies, and earnings quality. Peasnell et al. (2016) report a negative relationship between analysts’ stock recommendations and stock price volatility. Both studies find that the effect of market beta is mixed.

A number of studies have shown that earnings-based multiples (e.g., P/E, EV/EBITDA) are the most popular valuation methods used in practice (Cascino et al. 2014). Imam et al. (2008)

\footnotetext{
${ }^{4} g_{2}=\left[\left(e p s_{2}-e p s_{1}\right) / e p s_{1}+r \times d p s_{1} / e p s_{1}\right] . g_{2}$ captures the usual measure of EPS growth in FY2. It also reflects an adjustment for foregone earnings as a result of dividends distribution $\left(d p s_{1}\right)$.

${ }^{5}$ For a firm that pays out all its earnings as dividends, it can be shown that $(\gamma-1)$ equals the long-run growth rate in the firm's expected earnings per share.

${ }^{6}$ The Gordon and Shapiro (1956) constant growth model is commonly used to establish theoretical linkages between the P/E multiple and growth and risk factors. The constant growth model, however, relies on an assumption of a 100 per cent payout ratio that equates growth rates in earnings per share and dividends per share. As Equation (2) makes clear, this assumption is partially relaxed in the OJ model, by making a distinction between near-term growth, $g_{2}$, and long-term growth, $\gamma-1$, which is assumed to be constant.
} 
examine UK analysts' use of valuation models by interviewing a sample of 35 sell-side and seven buy-side analysts and by analysing 98 research reports issued by the interviewees over the period 2000-2003. The authors report that analysts perceive that the importance of the discounted cash flow model (DCF) has significantly increased over time and is greater than reported in early survey studies. The results of their content analysis provide support for this finding. Nevertheless, they find that the importance of P/E multiple continues, and that valuation multiples rather than DCF are relied on for the determination of target prices. Peasnell and Yin (2014) examine 200 Investext research reports of U.S. firms issued by analysts of leading brokerage firms in 2011-2012 and find that earnings multiples are used for the determination of target prices in 60 per cent of the reports while DCF is used in only 18 per cent of the reports. In short, prior research shows that earnings multiples remain the most frequently used method in analysts' valuations, at least in the U.S., although the use of DCF may have increased over time.

\section{Hypotheses development}

We formulate three hypotheses based on the theoretical work of GD and OJ, evidence from broker reports, and recent empirical findings on analysts' risk analyses. Analysts normally provide one- and two-year ahead earnings per share forecasts (EPS 1 and EPS 2 , respectively) and an estimate of earnings growth for the next three to five years (i.e., long-term growth forecasts). While expectations about growth in future earnings beyond the three to five-year forecast horizon likely affect analysts' target P/E multiples, such information is not available to researchers and, thus, is omitted from our empirical analyses. It is important to note that the analyst's relative valuation approach likely captures at least partially the elements (industry prospects, a firm's industry position, and management quality) that, according to GD, influence 
earnings growth beyond analysts' forecast horizon since the average forward P/E multiples of comparable firms should reflect the market's view of the industry's long-run growth prospects. Furthermore, within the analyst industry coverage universe, stronger and more successful firms are expected to receive higher P/E multiples.

Lui et al. (2007) and Peasnell et al. (2016) identify several factors that appear to play a role in analysts' risk adjustments and we include the most important of these as explanatory variables in this study. The variables include stock price volatility, size and book-to-market risk proxies, and financial leverage. Although empirical evidence of the effect of market beta on analysts’ decisions is mixed, because of its theoretical importance and long history as a measure of riskiness, we include it in our empirical analysis.

In their research reports, analysts often provide explanations for why they issue earnings multiple premiums/discounts for specific firms within their industry coverage universe. For example, the following excerpt was taken from an Investext report on Pfizer provided by Credit Suisse First Boston analysts:

This target P/FE (price to forecasted earnings multiple) considers the company's growth outlook compared to that of its peers - a stronger outlook justifies a premium while a weaker outlook a discount. Pfizer's growth prospects are the second lowest in the U.S. Major Pharmaceutical Group, and we assign a 25\% relative P/FE discount to drug group peers. $^{7}$

Based on prior literature and broker reports, we predict that, within the analyst's industry coverage universe, firms with higher growth in expected earnings will receive higher price-future earnings multiples, while riskier firms will receive lower price-future earnings multiples. Valuation textbooks (e.g., Penman 2013) suggest that one of the key steps of multiples-based valuation is applying an average or median of the comparable firms' multiples to the target

\footnotetext{
${ }^{7}$ See Pfizer Inc. report, Credit Suisse First Boston Corporation, January 9, 2005.
} 
firm's earnings forecast to obtain its value estimate. Some researchers (e.g., Lundholm and Sloan 2013) argue that the relative valuation approach incorporates little information about expected future payoffs on which the value of the business hinges. If analysts subscribe to this textbook approach and naively apply industry average multiples, we would not be able to observe the relationships we predict. Hypothesis 1 (in alternative form) is thus:

H1: Within the analyst's industry coverage universe, the valuation (P/E multiple) premium that a firm receives is an increasing function of its growth premium relative to comparable firms and a decreasing function of its excess riskiness relative to comparable firms.

In terms of specific indicators of future profitability, GD suggest that readily measurable factors such as past profitability, progress, and stability are among the likely determinants of earnings multiples. ${ }^{8}$ We predict that a firm's more favourable showing on these variables will result in higher earnings multiples. Thus, Hypothesis 1a (in alternative form) is as follows:

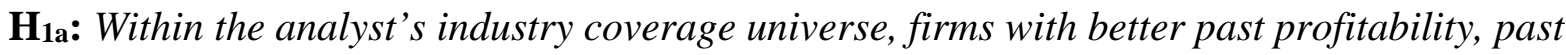
growth, and more stable earnings receive valuation (P/E multiple) premiums relative to comparable firms.

GD suggest that a logical approach to selecting the earnings multiple is to study past multiples, and either accept or modify them. However, they stress that analysts should avoid using historical multiples without careful consideration because a firm's prospects and quality can change dramatically over time and, importantly, the analyst must assess the accuracy of the market's valuation.

\footnotetext{
${ }^{8}$ Economic theory suggests that under competitive market conditions, high profitability will revert to the mean over the long run (Stigler 1963). We recognize that the economic rule of profitability mean reversion may impact analysts' earnings expectations, and thus their choices of P/E multiples.
} 
Evidence from broker reports suggests that analysts examine both historical earnings multiples and comparable firms' forward P/E multiples. For example, a Morgan Stanley (2007) research report states that it is more useful to understand not just how a stock valuation compares to its peers, but whether the stock is under- or over-valued within the historical context. We hypothesize that firms that are expected to have more (less) attractive fundamentals than their historical records, such as higher growth rates in expected earnings and lower expected risks, will be assigned target $\mathrm{P} / \mathrm{E}$ multiples that are at a premium (discount) to their long-run historical averages. Hypothesis 2 (in alternative form) is as follows:

H2: Firms that are expected to have stronger (weaker) fundamentals than they have had in the past will receive premium (discounted) P/E multiples relative to their average historical market P/E multiples.

To test these hypotheses, we follow prior practice and specify our main regressions such that the dependent variable is not the $\mathrm{P} / \mathrm{E}$ multiple premium but rather its reciprocal, the E/P multiple premium. We do this for two reasons. First, this approach facilitates comparison with prior research. Beaver and Morse (1978) and Zarowin (1990) motivate the use of E/P in part because they derive it from Litzenberger and Rao (1971) where the relationships between E/P and growth and risk are linear. Second, we use E/P to minimise scaling problems. White (2000) and Dudney et al. (2008) use E/P because it is better behaved in a statistical sense: when the scaling variable approaches zero, it can result in very large outliers that distort the regression relationship. ${ }^{9}$

\footnotetext{
${ }^{9}$ As an untabulated sensitivity test, we re-estimate the regressions in the study using analyst target P/E multiples (as opposed to the inverse $\mathrm{E} / \mathrm{P}$ measures used in our main tests) as the dependent variables. We eliminate observations with negative $\mathrm{EPS}_{1}$ forecasts. We also eliminate a small portion of observations with the lowest (2, 3, and 5 per cent) EPS $_{1}$ forecasts in an attempt to minimize the scaling problems (i.e., very large outliers) that might arise when the scaling variable $E P S_{1}$ approaches zero in the calculation of analyst target $\mathrm{P} / \mathrm{E}$ multiples. The regression results are consistent with those based on analyst E/P multiples, and all inferences are the same. One notable difference, to be expected given the volatile nature of the P/E multiple variable, is that the adjusted $R^{2} \mathrm{~s}$ of the regressions are significantly lower than those based on the E/P multiples.
} 


\section{Variables and Empirical Models}

\subsection{Variable definitions}

We obtain a proxy for analyst target P/E multiple $\left(\widehat{P}_{t+1} / E P S_{1}\right)$ by dividing the analyst's (typically, one-year-ahead) target price forecast, $\hat{P}_{t+1}$, by her EPS ${ }_{1}$ forecast, both issued at date $t$ and collected from the Institutional Brokers' Estimate System (I/B/E/S). This allows us to generate a large dataset of proxies for analyst target $\mathrm{P} / \mathrm{E}$ multiples that would not be possible if we hand-collected analyst target P/E multiples from broker reports. Some researchers suggest that analyst choices of valuation methods may vary by economic sector (e.g., Barker 1999b, Demirakos et al. 2004). Overall, however, evidence on the type(s) of multiples analysts apply to value firms by industry is rather limited. Consequently, we do not have sufficient evidence to exclude firms in certain industries from our sample. Importantly, our review of analyst reports reveals that in the case where the $\mathrm{P} / \mathrm{E}$ multiple is not the dominant valuation method, analysts frequently appear to use the P/E multiple method to triangulate the target price forecast derived from other valuation methods. We conduct our main empirical tests for both the pooled sample and subsamples of economic sectors.

We examine two measures of analysts’ earnings growth forecasts: analysts’ long-term growth forecasts (LTG) and their near-term growth forecasts $\left(G_{2}\right) . G_{2}$ is calculated using the formula: $\left(E P S_{2}-E P S_{1}\right) / E P S_{1}$.

We examine the following risk measures: financial leverage ( $L E V)$, measured as the total liability-to-total assets ratio; stock price volatility (VOL), measured as the annualized standard deviation of historical daily returns over the prior twelve-month period; size (Size), measured as the natural logarithm of market value; the book-to-market ratio (B/M); and market beta (Beta), derived from a time series regression of monthly stock returns on corresponding market returns 
over the prior sixty months.

We measure past profitability, stability, and past growth using the gross margin ratio at the beginning of the EPS 1 forecast period $(G M)^{10}$, earnings volatility in the last five years $\left(\right.$ Earn $\left._{v o l}\right)$, measured as the standard deviation of the past five years' earnings before extraordinary items deflated by total assets, and the actual sales growth rate in the last five years ( $\left.A G_{\text {sales }}\right)$, respectively. We calculate $A G_{\text {sales }}$ by fitting a least squares growth line to the logarithms of six annual sales observations.

The OJ model assumes that there is no relation between a firm's dividend payout policy and its P/E ratio, consistent with the early work of Miller and Modigliani (1961). Since an analyst's forecasted target price represents her best estimate of the stock's price at the end of the forward twelve-month period, it is an ex-dividend value estimate. Ceteris paribus, analysts likely assign lower P/E multiples to firms with higher dividend yields to adjust for the expected reduction in the firm's value resulting from dividends distribution. Thus, we include analyst forecasted dividend yield (DY) as a control variable in our models. ${ }^{11}$

\footnotetext{
${ }^{10}$ The review of broker reports and evidence in Peasnell and Yin (2014) suggests that analysts frequently use the gross margin ratio to forecast future earnings by multiplying forecasted sales by the gross margin ratio to obtain forecasted gross profit. Based on this evidence, we use gross margin ratio to measure past profitability in this study. Return on Equity (ROE) and the operating gross margin ratio would also be possibilities here. However, ROE exhibits a strong mean reversion tendency over the long run due to competition (e.g., Freeman et al. 1982, Fama and French 2000). Hence, it may act as a proxy for the expected future profitability in our tests, and therefore may not be suitable for testing GD's assertion relating to the positive effect of past profitability on target P/E multiples. The operating gross margin ratio exhibits weaker mean reversion tendency than ROE, possibly due to the fact that technology and cost structure differ across industries (Nissim and Penman 2001), but it is also less stable and less useful than the gross margin ratio for forecasting earnings. As a sensitivity check, we re-ran all our empirical tests using both ROE and the operating gross margin ratio to measure past profitability. We find that analyst E/P multiple premiums are positively associated with the industry average-adjusted ROE and the operating gross margin ratio, suggesting that those measures acted more like proxies for future profitability. We interpret the results as suggesting that analysts expect future profitability of firms with high past ROE and operating gross margin ratio to revert to the mean (decay) over the long run and therefore issue higher target E/P multiples. We find similar results when ROE and the operating gross margin ratio are used in the historical average-adjusted tests.

${ }^{11}$ Analyst target E/P multiple is similar to an ex-dividend yield. Instead of correcting analyst target E/P multiples by adding the dividend yield, we prefer to include the dividend yield as a control variable.
} 


\subsection{Model for assessing analysts' relative valuations based on comparable firms}

We test Hypothesis 1 by examining the relationships between the E/P multiple premiums/discounts firms received from the analysts, and their growth and risk premiums relative to comparable firms. To analyse Hypothesis 1a, we examine whether firms that outperform comparable firms in terms of past profitability, progress, and stability (PPS) receive premium E/P multiples relative to comparable firms. Therefore, if we let $i$ denote the target firm, and $\theta_{i}$ denote the corresponding comparable group (i.e., the combination of firm $i$ and its comparable firms), and let $j$ be the index of firms belonging to the comparable group $\theta_{i}$, we can analyse the relationships in Equation (3) as follows:

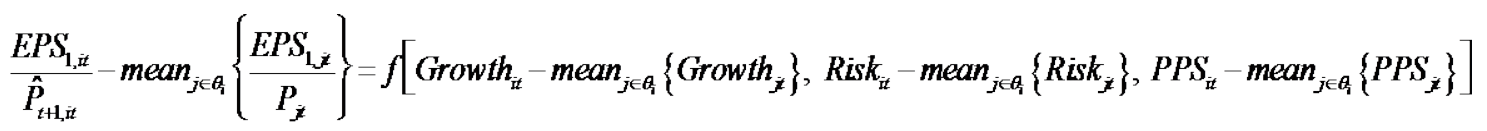

where $\frac{E P S_{1, i t}}{\hat{P}_{t+1, i t}}$ denotes the analyst target $\mathrm{E} / \mathrm{P}$ multiple assigned to firm $i$ at date $t$, calculated based on the EPS ${ }_{1}$ and target price forecasts of firm $i$ issued by the analyst at date $t . \frac{E P S_{1, j t}}{P_{j t}}$ is the forward E/P multiple of firm $j$, calculated by dividing firm $j$ 's one-year-ahead earnings per share forecast issued in the date $t$ calendar quarter, $E P S_{1, j t}$, by firm $j$ 's current price, $P_{j t}$. Growth $h_{i t}$ represents the expected earnings growth rate of firm $i$ at date $t$, Riskit represents the expected riskiness of firm $i$ at date $t$, and $P P S_{i t}$ represents firm i's past profitability, progress and stability.

The dependent variable in Equation (3) is the difference between the analyst target E/P multiple of firm $i$ and the average forward E/P multiple ${ }^{12}$ of firms in the comparable group $\theta_{i}$, and, as such, represents the $\mathrm{E} / \mathrm{P}$ multiple premium that firm $i$ receives from the analyst. The

\footnotetext{
12 Our reading of broker reports suggests that, in estimating industry average multiples, analysts do not appear to use the 'out-of-sample' approach. We therefore follow this practice and adopt the 'in-sample' approach for our empirical analysis here.
} 
variable Growth $_{i t}-$ mean $_{j \in \theta_{i}}\left\{\right.$ Growth $\left._{j t}\right\}$ represents the expected growth premium of firm $i$ relative to its comparable firms, $\operatorname{Ris}_{i t}-$ mean $_{j \in \theta_{i}}\left\{\operatorname{Risk}_{j t}\right\}$ represents the relative excess riskiness of firm $i$, and $P P S_{i t}-$ mean $_{j \in \theta_{i}}\left\{P P S_{j t}\right\}$ represents the past profitability, progress, and stability of firm $i$ relative to comparable firms.

We use I/B/E/S data to construct a proxy for the analyst industry coverage universe (the comparable group). Analysts generally specialize in only a limited number of industries and a relatively small number of firms (e.g., Boni and Womack 2006). As such, firms within an analyst's industry coverage universe should be deemed to be the relevant set of comparable firms (Alford 1992, Boni and Womack 2006). Boni and Womack (2006) suggest that industry divisions based on the third level of the S\&P/MSCI Global Industry Classification Standard (GICS) - 'Industry' - provide a good proxy for how firms are covered by analysts. We therefore designate firms with the same third-level GICS code and covered by the same analyst as a comparable group. We then compute the E/P multiple premium, the growth premium, and the excess riskiness of firm $i$ relative to its comparable firms, and similar relative measures of gross margin ratio, sales growth, and earnings volatility in three steps.

First, we divide observations with target price forecasts issued by individual analysts along three dimensions, by analyst, by third-level GICS industry code, and by calendar year-quarter, in order to obtain analyst-industry-calendar quarter combinations. Our sample indicates that analysts, on average, issue four target price forecasts per firm per year. We choose one calendar quarter as the time span for the calculation of comparable group means.

Second, for each analyst-industry-calendar quarter unit that contains at least three distinct firms, we calculate: (1) the mean forward E/P multiple for the comparable group, $\operatorname{mean}_{j \in \theta_{i}}\left\{\frac{E P S_{1, j t}}{P_{j t}}\right\}$, and (2) the means of the two growth measures, the risk measures, the gross 
margin ratio, the actual five-year sales growth rate, and earnings volatility for the comparable group, with each firm equally weighted where multiple observations of a firm fall within the same calendar quarter. For ease of notation, the resulting means are referred to as industry means rather than comparable group means. We require the number of comparable firms (including the target firm) in an analyst-industry-calendar quarter combination to be at least three, which is a compromise between (1) having enough observations to avoid excessive noise, and (2) not unduly reducing the sample size. We require each analyst-industry-calendar quarter to have industry means greater than zero for all variables, a condition necessary for the calculation of percentages in the next step.

Third, our methodology requires that we construct a measure of the E/P multiple premium that is comparable across firms and analysts. Thus, we compute a percentage E/P multiple premium for the target firm by taking the difference between its analyst target E/P multiple and the mean forward E/P multiple of the corresponding comparable group, and then normalizing the result by the same mean forward $\mathrm{E} / \mathrm{P}$ multiple. Likewise, we compute a percentage growth premium (excess riskiness relative to comparable firms) for the target firm by computing the difference between its earnings growth rate (risk level) and the mean earnings growth rate (risk level) of the comparable firms. We then scale the result by the same mean growth rate (risk level) of the comparable group.

We calculate the industry mean-adjusted forecasted dividend yield, gross margin ratio, past sales growth, and earnings volatility in a similar fashion. We use the superscript 'ind_adj' to differentiate the obtained industry mean-adjusted relative measures, expressed as percentages, from the variable levels. We estimate Equation (4) to analyse Hypotheses 1 and 1a: 


$$
\begin{aligned}
\left(\frac{E P S_{1, i t}}{\hat{P}_{t+1, i t}}\right)^{\text {premium }} & =\alpha+\beta_{1} L T G_{i t}^{\text {ind_adj }}+\beta_{2} G_{2, i t}^{\text {ind_adj }}+\beta_{3} L E V_{i t}^{\text {ind_adj }}+\beta_{4} V O L_{i t}^{\text {ind_adj }}+\beta_{5} S_{i z e_{i t}^{i n d} \_a d j}+\beta_{6} B M_{i t}^{\text {ind_adj }} \\
& +\beta_{7} \text { Beta }_{i t}^{\text {ind_adj }}+\beta_{8} D Y_{i t}^{\text {ind_adj }}+\beta_{9} G M_{i t}^{\text {ind_adj }}+\beta_{10} A G_{\text {sales,it_adj }}^{\text {ind_adj }}+\beta_{11} E a r n_{v o l, i t}^{\text {ind_adj }}+\varepsilon_{i t}
\end{aligned}
$$

where $\left(\frac{E P S_{1, i t}}{\hat{P}_{t+1, i t}}\right)^{\text {premium }}$ represents firm $i$ 's E/P multiple premium as a percentage of the mean forward E/P multiple of the comparable group assigned by the analyst at date $t . L T G_{i t}^{\text {ind } \_a d j}$ and $G_{2, i t}^{\text {ind_adj }}$ represent the two relative growth premiums of firm $i$ forecasted at date t. $L E V_{i t_{-}}^{\text {ind adj }}$,

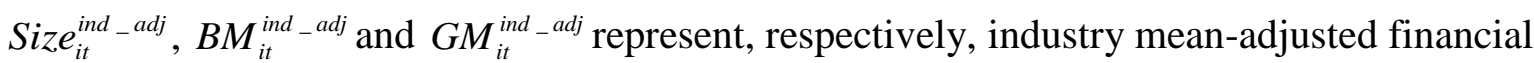
leverage, size, book-to-market, and gross margin ratio, calculated using the variable levels at the beginning of the EPS ${ }_{1}$ forecast period. $D Y_{i t}^{\text {ind }}{ }_{-}^{a d j}$ represents the industry mean-adjusted forecasted dividend yield, estimated using the dividend forecast issued at date $t$ and price at date t. $\mathrm{VOL}_{i t_{-}}^{\text {ind } a d j}$ and $\mathrm{Beta}_{i t_{-}}^{\text {ind }{ }^{a d j}}$ represent, respectively, industry mean-adjusted stock price volatility and market beta estimated at date $t . A G_{\text {sales,it }}^{\text {ind_adj }}$ and $E a r n_{v o l, \text { it }}^{\text {ind }}{ }^{\text {adj }}$ represent industry meanadjusted sales growth rate and earnings volatility of the past five years, respectively.

Hypothesis 1 predicts that the coefficients of both $L T G^{\text {ind_adj }}$ and $G_{2}{ }^{\text {ind_adj }}$ will be negative. Hypothesis 1 predicts that the coefficient of Size $e^{i n d a d j}$ will be negative, while those of $L E V^{\text {ind_adj }}$, $V O L^{\text {ind_adj }}$, and $B M^{\text {ind_adj }}$ will be positive. Note that we make no predictions about the coefficient of Beta ${ }^{\text {ind_adj }}$, given that existing evidence on the effect of market beta is mixed. Hypothesis 1a predicts that the coefficients of $G M^{\text {ind_adj }}$ and $A G_{\text {sales }}^{\text {ind_adj }}$ will be negative, and that of $\operatorname{Earn}_{\text {vol }}$ ind_adj will be positive.

\subsection{Model for assessing analyst valuations by benchmarking to historical averages}

We calculate deviations of the analyst's target E/P multiple, the firm's growth and risk 
measures, and other past performance-based measures from their respective long-run averages using ten years of historical data. We add the superscript 'Dev_HisAvg' to the resulting variables to indicate deviation from historical averages.

We estimate Equation (5) to test Hypothesis 2:

$$
\begin{aligned}
\left(\frac{E P S_{1, i t}}{\hat{P}_{t+1, i t}}\right)^{\text {Dev_HisAvg }}= & \alpha+\beta_{1} L T G_{i t}^{\text {Dev_HisAvg }}+\beta_{2} G_{2, i t}^{\text {Dev_HisAvg }}+\beta_{3} L E V_{i t}^{\text {Dev_HisAvg }}+\beta_{4} V O L_{i t}^{\text {Dev_HisAvg }} \\
& +\beta_{5} \text { Size }_{i t}^{\text {Dev_HisAvg }}+\beta_{6} B M_{i t}^{\text {Dev_HisAvg }}+\beta_{7} \text { Beta }_{i t}^{\text {Dev_HisAvg }}+\beta_{8} D Y_{i t}^{\text {Dev_HisAvg }} \\
& +\beta_{9} G M_{i t}^{\text {Dev_HisAvg }}+\beta_{10} A G_{\text {sales,it_ }}^{\text {Dev_Hisavg }}+\beta_{11} \text { Earn }_{\text {vol, }, i t}^{\text {Dev_HisAvg }}+\varepsilon_{i t}
\end{aligned}
$$

where $\left(\frac{E P S_{1, i t}}{\hat{P}_{t+1, i t}}\right)^{\text {Dev_HisAvg }}$ is the difference between firm i's analyst target E/P multiple at date $t$ and the average historical (forward) E/P multiple at which firm $i$ traded in the past. We calculate the historical E/P multiple for a firm for a given year by dividing the consensus monthly EPS 1 forecast estimated by $\mathrm{I} / \mathrm{B} / \mathrm{E} / \mathrm{S}$ in December ${ }^{13}$ of that year by the Centre for Research in Security Prices (CRSP) listing price of the firm on the day the consensus EPS ${ }_{1}$ forecast was estimated. To calculate the average historical E/P multiple of the firm, we take a simple average of the firm's E/P multiples over the ten years prior to the year the target price forecast was released.

$L T G_{i t}^{\text {Dev_HisAvg }}$ denotes the difference between the LTG forecast issued by the analyst at date $t$ and the average LTG forecasts of the firm over the last ten years, which is calculated by using

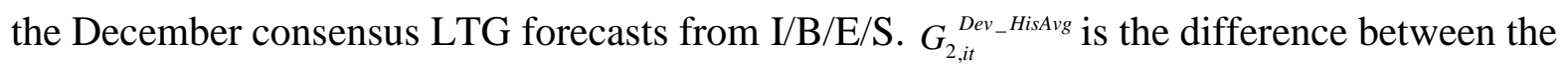
near-term growth forecast estimated at date $t$ and the ten-year average of the variable, calculated

\footnotetext{
${ }^{13}$ Richardson et al. (2004) suggest that analysts tend to issue optimistic EPS ${ }_{1}$ forecasts at the beginning of the fiscal year, and they revise down the upward bias in their forecasts as the fiscal year end approaches. Given that the

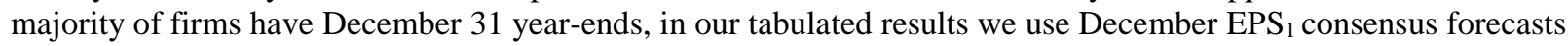
in order to reduce the influence of time-dependent factors that might introduce potential noise. Similarly, we use December consensus EPS 1, EPS $_{2}$ and LTG forecasts for the calculation of ten-year historical averages of $\mathrm{G}_{2}$ and LTG. As a sensitivity test, we used consensus (EPS $1, E_{1} S_{2}$ and LTG) forecasts released in the months in which individual firms' fiscal years end for the empirical analysis and obtained essentially the same results.
} 
using the monthly consensus forecasts of EPS ${ }_{1}$ and EPS $_{2}$ estimated in each December of the past ten years. $L T G_{i t}^{\text {Dev_HisAvg }}$ and $G_{2, i t}^{\text {Dev_Hisavg }}$ denote the expected growth premiums of firm $i$ relative to its historical averages, while $D Y_{i t}^{\text {Dev_HisAvg }}, L E V_{i t}^{\text {Dev_HisAvg }}, \operatorname{Size}_{i t}^{\text {Dev_HisAvg }}$, and $B M_{i t}^{\text {Dev_HisAvg }}$ are the deviations of the forecasted dividend yield and leverage, size, and book-to-market of the last fiscal year from their respective historical averages. Again, each of these variables is calculated using the reported financial data of the ten years prior to the most recent fiscal year and, in the case of the forecasted dividend yield, the actual dividend yield of the last ten years.

We calculate stock price volatility and market beta for each of the ten years prior to the year the target price forecast was released. We use $\mathrm{VOL}_{\text {it }}^{\text {Dev_HisAvg }}$ and Beta ${ }_{i t}^{\text {Dev_HisAvg }}$ to represent the deviations of stock price volatility and market beta estimated at date $t$ from their ten-year averages. We use $G M_{\text {it }}^{\text {Dev_HisAvg }}, A G_{\text {sales, it }}^{\text {DevHisAvg }}$ and $\operatorname{Earn}_{\text {vol, it }}^{\text {Dev_HisAvg }}$ to represent respectively the deviations of gross margin ratio, the actual five-year sales growth rate, and earnings volatility from their ten-year averages.

Hypothesis 2 predicts the coefficients of $L T G^{\text {Dev-HisAvg }}, G_{2}{ }^{\text {Dev-HisAvg }}$, and Size ${ }^{\text {Dev-HisAvg }}$ will be negative, while those of $L E V^{\text {Dev-HisAvg }}, V O L^{\text {Dev-HisAvg }}$, and $B M^{\text {Dev-HisAvg }}$ will be positive. We predict the coefficient of $D Y^{\text {Dev-HisAvg }}$ will be positive.

Economic theory predicts that competition affects the profitability of comparable firms in the same industry similarly. It is unclear whether analysts properly consider the implication of profitability being mean reverting in their comparative analyses, but it is highly likely that it impacts the analyst's projection of the target firm's earnings in future periods. To the extent that analysts believe that high past profitability and growth predict a deceleration of earnings growth in subsequent years as a result of profitability mean reversals, $G M^{\text {Dev-HisAvg }}$ and $A G_{\text {sales }}^{\text {Dev-HisAvg }}$ 
will be positively associated with $\left(\frac{E P S_{1}}{\hat{P}_{t+1}}\right)^{\text {Dev_HisAvg }}$. However, the coefficients of $G M^{D e v-H i s A v g}$ and $A G_{\text {sales }}{ }^{\text {Dev-HisAvg }}$ will be negative if analysts assign firms valuation premiums based on above long-run average gross margin ratios and sales growth. We predict the coefficient of Earn $_{\text {vol }}{ }^{\text {Dev_HisAvg }}$ will be positive but make no prediction about the coefficient of Beta ${ }^{\text {Dev-HisAvg }}$.

\section{Data}

We obtain analyst forecasts of target price, long-term growth, EPS 1 , EPS 2 , and dividends for all U.S. firms for the 2000-2013 period from the I/B/E/S detail file, which contains individual analyst forecasts. We matched and merged individual target price forecasts and EPS ${ }_{1}$ and $\mathrm{EPS}_{2}$ based on issuance dates. On average, these analysts issued only 1.78 long-term growth forecasts for each firm each year. To avoid a significant loss of data, we required the latest long-term growth forecasts to be less than 365 days old. These forecasts were merged with target price forecasts. To compute the near-term earnings growth rate, $G_{2}$, we eliminated any observations with negative $\mathrm{EPS}_{1}$ forecasts because it is difficult to make economic sense of $G_{2}$ when $\mathrm{EPS}_{1}$ is negative. ${ }^{14}$

We use return and price data from CRSP to estimate stock price volatility, market beta, and forecasted dividend yields. The accounting data used to compute risk and past performance measures are taken from the COMPUSTAT files.

The relative infrequency of LTG forecasts and target price forecasts, as well as the inconsistency between their issuance dates, led to major data losses, as did the unavailability of

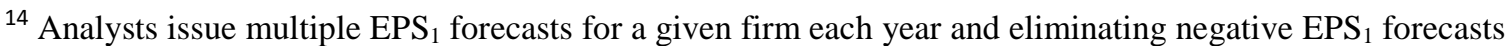
does not lead to loss of a significant number of firm-year observations or sample firms. This procedure does not affect the inferences of our study.
} 
certain GICS industry classification codes. Our original sample contains 92,082 observations, including 4,574 analysts and 3,524 distinct firms. To compute the industry mean-adjusted relative measures, we required each analyst-industry-calendar quarter to contain at least three distinct firms. To mitigate the effect of outliers, we excluded the lowest and highest 1 percentile of all variables used in the empirical analysis. After applying these data requirements, our sample for estimating Equation (4) was reduced to 32,028 observations, covering 2,323 distinct firms and 1,734 analysts. To calculate the deviations of variables from their historical averages, we require each analyst-target price forecast observation to have ten years of data for the calculation of the historical averages of all variables. This requirement resulted in significant data loss. Consequently, our sample for estimating Equation (5) consists of 29,968 observations, covering 958 distinct firms and 2,749 analysts.

Panel A of Table 1 presents the descriptive statistics for the variable levels of the sample. The mean and median of the proxy for analyst target E/P multiple, $\frac{E P S_{1}}{\widehat{P}_{t+1}}$, are 0.052 and 0.049 , respectively. Inverting the multiple, we find that half of the proxies for target P/E multiples are equal to or above 20.41 and half are below. The mean and median of LTG are 0.163 and 0.150 , respectively. The mean and median of $G_{2}$ are higher than those of $L T G$, at 0.262 and 0.163 , respectively. Panel B of Table 1 reports the descriptive statistics of the percentage E/P multiple premium and the industry mean-adjusted growth, risk, and other variables.

Panel C of Table 1 shows the statistics for the measures of deviation for the variables in panel A using their ten-year averages. The mean and median of $\left(\frac{E P S_{1}}{\hat{P}_{t+1}}\right)^{\text {Dev_HisAvg }}$ are 0.012 and 0.010, respectively. The mean and median of $L T G^{\text {Dev_HisAvg }}(-0.017$ and -0.016$)$ and those of $G_{2}{ }^{\text {Dev_HisAvg }}(-0.049$ and -0.025$)$ are negative. This suggests that analyst expectations about the firms’ growth prospects are lower than the ten-year averages of the consensus forecasts. For 
brevity, we omit discussion of the other variables in the table.

Panel A of Table 2 presents the correlations between the industry mean-adjusted measures

and firms' E/P multiple premiums relative to comparable firms $\left(\frac{E P S_{1}}{\hat{P}_{t+1}}\right)^{\text {premium }}$. As predicted, the correlations between the E/P multiple premiums and the two growth premium measures and the industry mean-adjusted gross margin ratio and the actual five-year sales growth rate are all negative. The E/P multiple premiums are positively correlated with the industry-mean adjusted financial leverage and book-to-market. The correlations between the E/P multiple premiums and other measures of excess riskiness are not consistent with our predictions. Panel B of Table 2 presents the correlations between the measures that reflect deviations of variables from their historical means. The correlations between $\left(\frac{E P S_{1}}{\hat{P}_{t+1}}\right)^{\text {Dev_HisAvg }}$ and $L T G^{\text {Dev_HisAvg }}$ and $G_{2}{ }^{\text {Dev_HisAvg }}$ are negative, consistent with our prediction.

\section{Empirical results}

\subsection{Results of tests of Hypotheses 1 and $1 a$}

We estimate Equation (4) for both the pooled sample and the GICS sector subsamples to analyse Hypotheses 1 and 1a. The Durbin-Watson statistics of the regressions we perform are small, around 1.96. Following Petersen (2009), we address the dependence in the residuals by clustering standard errors on firm and year dimensions. The results of the regression analyses for the pooled sample are reported in panel A of Table $3 .{ }^{15}$ Models 1-3 in the panel analyses the effects of the two growth premium measures on target P/E multiples with the risk and dividend

\footnotetext{
${ }^{15}$ Where reference is made to variables in equations (4) and (5), time and firm subscripts are suppressed for compactness.
} 
yield explanatory variables added in Model 4 . Models 5 and 6 are designed to analyse the effect of the three past performance measures.

In model 1 , the coefficient of $L T G^{\text {ind_adj }}(-0.255, \mathrm{t}=-37.69)$ is statistically significant and negative, and this result persists in models 3, 4, 5, and 6. In model 2, the coefficient of $G_{2}{ }^{\text {ind_adj }}$ $(-0.162, t=-56.88)$ is negative and statistically significant, and the result holds in models 3,4 , 5, and 6. In model 3, the coefficients of the two measures of growth premium remain negative and significant.

GD suggest that market participants and analysts place excessive emphasis on firms' nearterm performance. The magnitude of the explanatory power of $G_{2}{ }^{\text {ind_adj }}(22 \%)$ in model 2 suggests that analysts do, in fact, place significant weight on the near term in their valuations. ${ }^{16}$

In model 4, the coefficient of $L E V^{\text {ind } \_a d j}(0.188, \mathrm{t}=23.29)$ has the predicted sign and is statistically significant, suggesting that, within the analyst's industry coverage universe, firms with higher financial risk receive higher E/P multiples. The coefficient of $B M^{\text {ind_adj }}(0.141, \mathrm{t}=$ 24.31) also has the predicted positive sign. The coefficient of Size $e^{\text {ind_adj }}(0.045, \mathrm{t}=2.27)$ has the wrong sign and is also statistically significant at the 5 per cent level. This result suggests that, for our sample period, analysts assigned lower E/P multiples to smaller firms within the analysts' industry coverage universe. The result suggests that Lui et al.’s (2007) finding that risk assessments of Salomon Smith Barney factor in size as a risk factor does not apply to our sample. The coefficient of $V O L^{\text {ind_adj }}(-0.038, \mathrm{t}=-2.97)$ has the wrong sign and is statistically

\footnotetext{
${ }^{16}$ It is important to note that this study does not attempt to compare the effects of $G_{2}$ and $L T G$ on analyst target $\mathrm{P} / \mathrm{E}$ multiples. One needs to be cautious about making such a comparison for two reasons. First, there is not sufficient theoretical support for the argument that analysts place more weight on $G_{2}$ than $L T G$. Existing evidence (e.g., Bradshaw, 2004) suggests that long-term growth forecasts play an important role in analysts' stock recommendation decisions. Second, analysts issue long-term growth forecasts much less frequently than target price forecasts. We match target P/E multiples with long-term growth forecasts of less than 365 days to avoid significant loss of observations. We expect this procedure and the stickiness of LTG forecasts to impact the strength of the statistical association between $L T G$ and target P/E multiples and limit our ability to make a valid comparison.
} 
significant. Additional analysis, however, reveals that this result is driven by observations in years 2011 and 2013 during which the U.S. stock markets were exceptionally bullish. When observations from years 2011 and 2013 are excluded, the (untabulated) coefficient of VOL ind_adj is not statistically significant, which may be attributable to the fact that the level of stock price volatility is more informative than the industry mean-adjusted measure of the variable. For example, Morgan Stanley analyst reports identify stocks that are expected to have more than a $25 \%$ chance of a price change (up or down) of more than $25 \%$ in a month as volatile stocks.

$\operatorname{Beta}^{\text {ind_adj }}(-0.001, \mathrm{t}=-0.21)$ is not associated with the E/P multiple premiums in Model 4. This result provides additional evidence that market beta appears not to be treated as a risk measure in analysts' analysis (e.g., Barker 1999a, Peasnell et al. 2016). Finally, the coefficient of $D Y^{i n \_\_a d j}(0.015, \mathrm{t}=6.07)$ has the predicted positive sign and is statistically significant, suggesting that firms expected to have a higher dividend yield receive higher $\mathrm{E} / \mathrm{P}$ multiples than comparable firms. In short, the results reported in model 4 provide strong support for Hypothesis 1.

Models 5 and 6 report the results of the regression analyses of the relationships between the E/P multiple premiums/discounts assigned by analysts and firms' relative measures of past profitability, growth, and stability. In model 5, the coefficients of $G M^{\text {ind_adj }}(-0.073, t=-8.16)$ and $A G_{\text {sales }}$ ind_adj $(-0.019, \mathrm{t}=-7.29)$ both have the predicted negative signs, indicating that, other things equal, firms with strong past profitability and growth tend to trade at higher earnings multiples. The coefficient of Earn $n_{v o l}{ }^{\text {ind } \_a d j}(-0.002, \mathrm{t}=-0.55)$ has the wrong sign but is not statistically significant. In model 6, the coefficients of $G M^{\text {ind_adj }}$ and $A G_{\text {sales }}{ }^{\text {indadj }}$ have the predicted negative sign but are not statistically significant. The coefficient of Earn vol $^{\text {ind_adj }}(0.011$, $t=2.71$ ) has the predicted positive sign and is statistically significant in the model, suggesting 
that analysts assign higher E/P multiples to firms with higher past earnings volatility. In short, the results reported in models 5 and 6 provide some support for Hypothesis 1a. Overall, the two measures of future earnings growth have a substantial effect on analysts' choices of target E/P multiples while past profitability and past growth measures have a rather limited effect.

We also estimate Equation (4) for subsamples of the GICS sectors ${ }^{17}$ and the results are reported in panel B of Table 3. Our finding that firms with more promising growth prospects relative to comparable firms receive lower E/P multiples generally holds across all sectors. $\left(\frac{E P S_{1}}{\hat{P}_{t+1}}\right)^{\text {premium }}$ is negatively associated with $G_{2}{ }^{\text {ind_adj }}$ for all sectors reported in the panel. The coefficient of $L T G^{\text {ind_adj }}$ has the predicted negative sign and is statistically significant at least at the 5 per cent level for all sectors. $L E V^{\text {ind_adj }}$ has the predicted sign and is statistically significant for seven out of the nine sectors. This suggests that analysts following most of the economic sectors appear to discount financial risk in selecting target P/E multiples. $B M^{\text {ind_adj }}$ has the predicted positive sign and is statistically significant in eight of the nine regression tests.

The effects of the remaining risk measures vary across industry sectors. Size $e^{\text {ind_adj }}$ has the predicted sign and is statistically significant for the materials sector. Beta ${ }^{\text {ind_adj }}$ has a positive sign and is statistically significant at least at the 5 per cent level in the regression tests of the materials and utilities sectors. The coefficient of VOL ${ }^{\text {ind_adj }}$ has the opposite sign to our expectations and is statistically significant for four sectors, likely due to the fact that the level of stock price

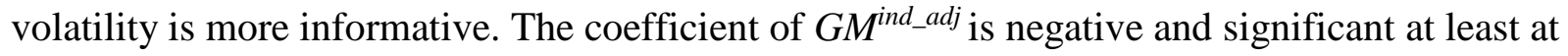
the 1 per cent level for consumer staples, industrials, information technology, and materials

\footnotetext{
${ }^{17}$ The sample size of the telecommunication services is not large enough (28 observations) for making reliable inferences. The regression analysis for that subsample is therefore omitted.
} 
sectors. Earn $_{v o l}$ ind_adj $^{\text {has }}$ the predicted positive sign and is statistically significant at least at the 10 per cent level in four of the regression tests.

The adjusted $R^{2} \mathrm{~s}$ of the regression tests for the consumer discretionary, consumer staples, healthcare, industries, information technology, and materials sectors are relatively high, ranging from 0.38 to 0.54 . This evidence mirrors the findings that analysts tend to apply earnings multiples to firms in the consumer goods (retail), service, and industrial sectors (Barker 1999b, Demirakos et al. 2004). ${ }^{18}$

\subsection{Results of tests of Hypothesis 2}

We estimate Equation (5) to test Hypothesis 2. The Durbin-Watson statistics of the tests we perform are small, around 1.98. We address the dependence in the residuals by clustering standard errors on firm and year dimensions. The results are reported in Table 4.

In model 1, the coefficient of $L T G^{\text {Dev-HisAvg }}(-0.041, \mathrm{t}=-11.64)$ is negative and statistically significant. This result suggests that firms with more promising growth prospects in the next three to five years relative to their long-run averages receive lower E/P multiples from analysts relative to the average forward E/P multiples at which they traded in the past. $L T G^{\text {Dev-HisAvg }}$ explains 2 per cent of the variation in the E/P multiple premiums assigned by analysts in model 1. The relatively low explanatory power of $L T G$ may be attributable to the fact that analysts' LTG forecasts are somewhat sticky.

In model 2, the coefficient of $G_{2}{ }^{\text {Dev-HisAvg }}(-0.031, \mathrm{t}=-21.67)$ is also negative and statistically

\footnotetext{
18 Prior literature and broker reports suggest that the earnings multiples represent a common measure of how expensive (cheap) stocks are in the market (e.g., Morgan Stanley 2012; Hsu et al. 2013). When analysts use valuation methods such as price-to-book value or the dividend yield model, for example, to value financial and utility firms, the results in the tables provide insight into their opinions on how many times forecasted earnings the stocks should trade.
} 
significant. This suggests that firms that were expected to have higher near-term growth rates than their long-run averages received lower $\mathrm{E} / \mathrm{P}$ multiples from analysts relative to the average historical forward E/P multiples at which they traded. $G_{2}{ }^{\text {Dev-HisAvg }}$ explains 11 per cent of the variation in E/P multiple premiums assigned by analysts in model 2. In model 3, both growth premium measures have the predicted negative sign.

In model 4, $L E V^{\text {Dev-HisAvg }}(0.010, t=3.09)$ is positively associated with the E/P multiple premiums assigned by analysts. This suggests that analysts issue discounted valuation multiples to firms with increased financial risk relative to their historical averages. The coefficient of $V O L^{\text {Dev-HisAvg }}(0.016, \mathrm{t}=11.84)$ has the predicted positive sign and is statistically significant. This suggests that firms with higher levels of stock price volatility than their historical averages received E/P multiples that were higher than the average historical forward E/P multiples at which they traded. This result holds in model 6 .

In model 4, the coefficient of $B M^{\text {Dev-HisAvg }}(0.010, t=4.37)$ has the predicted positive sign and

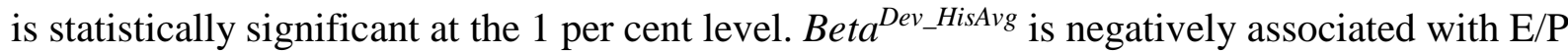
multiple premium. Size $e^{\text {Dev_HisAvg }}$ has the wrong sign in all models. This suggests that, for our sample period, increases in the firm's market value appear to adversely affect analysts' choices of earnings multiples. However, it is possible that Size $e^{\text {Dev_HisAvg }}$ simply captures fluctuations in stock price over time rather than changes in riskiness or captures a number of firm-specific factors, some of which could pull in the opposite direction. $D Y^{\text {Dev_HisAvg }}$ has the wrong sign and is statistically significant at the 5 per cent level in model 4 .

In model 5 , the coefficients of $G M^{\text {Dev_HisAvg }}(0.398, \mathrm{t}=6.48)$ and $A G_{\text {sales }}^{\text {Dev-HisAvg }}(0.043, \mathrm{t}=$ 10.84) are positive and statistically significant. This result suggests that firms with above historical average gross margin ratios and past sales growth received above historical average 
E/P multiples. One possible explanation for this result is that the analysts expect the high past profitability and growth to decline over the longer run as profitability reverts to the mean, and they assigned higher E/P multiples accordingly. Earn $_{v o l}{ }^{\text {Dev-HisAvg }}(-0.003, \mathrm{t}=-0.24)$ has the wrong sign but is not statistically significant in model 5 .

In model 6, the results of the explanatory variables remain the same qualitatively. To summarize, the results in Table 4 support Hypothesis 2 and suggest that analysts use historical multiples of target firms to determine whether the P/E multiples they select for the firms are outside historical norms, and whether the multiple premiums/discounts they assign are justified by the firms' fundamentals relative to historical averages.

\section{Additional analysis}

Analysts often reference the P/E multiples of broad market indexes such as the S\&P 500 Index in their research reports. We perform a preliminary analysis to provide some evidence on the possible linkages between the benchmark market index P/E multiple and analysts' choices of target P/E multiples.

The S\&P 500 forward P/E multiple reflects the market’s determination of how many times expected earnings the 500 large U.S firms constituting the index should collectively trade. It can serve as an additional benchmark in analysts' valuation analysis in several ways. First, the analyst may refer to the index's P/E multiple and determine that a firm with fundamentals stronger than the average performance of the S\&P 500 firms should trade at a premium to the P/E multiple for the S\&P 500 Index, and vice versa. Second, the P/E multiples for the S\&P 500 Index reflect the market's expectations about the growth prospects of the U.S. economy and macroeconomic factors such as interest rates, the market risk premium, the inflation rate, energy 
prices, etc. (e.g., Reilly et al. 1983, White 2000). The macroeconomic data embedded in the forward P/E multiples for the S\&P 500 Index are logically valuable inputs into analysts’ projections of financial results, given that firms’ future fundamental performance (e.g., sales, costs and earnings) are dependent on the growth prospects of the economy (e.g., the expected GDP growth) and macroeconomic conditions (Lundholm and Sloan 2013). We expect analysts to revise their expectations about firms’ growth and risk fundamentals, and hence their target P/E multiples, subsequent to shifts in the levels of the S\&P 500 P/E multiple driven by macroeconomic developments. In addition, Campbell and Shiller (1988) show that the historical average earnings of the S\&P 500 Index help predict the present value of the future dividends of the index. They find that as indicators of fundamental value relative to price, the E/P ratios of the index predict one- to ten-years future returns. Thus, a low S\&P $500 \mathrm{P} / \mathrm{E}$ ratio, and subsequent increases in the ratio, may be interpreted by analysts as an indicator that the stock market is currently undervalued and is in the process of adjusting to its fundamental value, and vice versa. This may prompt analysts to adjust the valuation multiples for target firms accordingly.

For the above reasons, we conjecture that analysts revise their target E/P multiples in the same direction as changes in the forward E/P multiple of the S\&P 500 Index. We estimate the following equation to test our prediction.

$$
\Delta\left(\frac{E_{1, i t}}{\hat{P}_{t+1, i t}}\right)=\alpha+\beta_{1} \Delta S P 500 E P_{t}+{\text { Control } \text { Variables }_{i t}}+\varepsilon_{i t}
$$

where the dependent variable represents the change in firm i's target E/P multiple, which is the difference between firm $i$ 's target E/P multiple assigned by the analyst at time $t$ and the previous target E/P multiple assigned by the analyst. $\triangle S P 500 E P_{t}$ represents the change in the forward $\mathrm{E} / \mathrm{P}$ multiple for the S\&P 500 Index (SP500EP) in the date $t$ calendar month. We predict that the coefficient on $\triangle S P 500 E P_{t}$ will be positive, reflecting analysts' reactions to changes in the market 
index P/E multiple. Our empirical model includes changes in the levels of the explanatory variables from Equation (4) as control variables. Specifically, we include changes in the two growth forecasts ( $\Delta L T G_{i t}, \Delta G_{2, i t}$ ), changes in financial leverage, stock price volatility, book-tomarket, size, and market beta ( $\triangle L E V_{i t}, \Delta V O L_{i t}, \Delta B M_{i t}, \Delta \log M V_{i t}$, and $\left.\triangle B e t a_{i t}\right)$, and changes in the dividend yield $\left(\Delta D Y_{i t}\right)$ and the past performance measures $\left(\Delta G M_{i t}, \Delta A G_{\text {sales }, i t}, \Delta E_{\left.a r n_{v o l, i t}\right)}\right.$.

We obtain information about the S\&P 500 Index constituencies from COMPUSTAT. We then collect three data items for each constituent firm from I/B/E/S: monthly consensus EPS 1 forecast $\left(E P S_{1 i}\right)$, the number of shares $\left(Q_{i}\right)$, and closing price $\left(P_{i}\right)$ on the announcement day of each month (the third Thursday). We calculate the E/P multiple (value-weighted) for the S\&P 500 Index each month using the following formula:

$$
S P 500 E P=\frac{\sum_{i} E P S_{1 i} \times Q_{i}}{\sum_{i} P_{i} \times Q_{i}}
$$

Table 5 reports the results of our regression tests. We address the potential dependence in residuals by clustering standard errors on firm and month dimensions. In model 1 , the coefficient of $\triangle \operatorname{SP500EP}(0.423, \mathrm{t}=12.07)$ is positive and statistically significant. This suggests that changes in the S\&P 500 Index E/P multiples are associated with changes in analyst target E/P multiples in the same direction. This single factor explains $5 \%$ of the variation in the changes of analyst target $\mathrm{E} / \mathrm{P}$ multiples. In model 2 , the coefficients of $\Delta L T G(-0.023, \mathrm{t}=-17.37)$ and $\Delta G_{2}$ $(-0.024, \mathrm{t}=-90.27)$ are negative and statistically significant. The coefficient of $\triangle S P 500 E P$ remains positive and statistically significant in the presence of $\Delta G_{2}$ and $\Delta L T G$.

In model 3, the result of $\triangle S P 500 E P$ remains unchanged qualitatively after the inclusion of additional risk and past performance control variables. The results of the control variables are largely consistent with those reported in Tables 3 and 4. In particular, increases in financial leverage, stock price volatility, and the book-to-market ratio are associated with upward 
revisions of analyst target E/P multiples. The change in market beta is positively associated with the change in analyst target E/P multiples. However, the economic effect of the variable is quite small.

\section{Sensitivity tests}

We performed several tests to assess the sensitivity of our results. First, we used the medians of the forward E/P multiples and other measures as benchmarks to construct industry medianadjusted measures. We then estimate Equation (4) using these variables and the results (untabulated) are consistent with those reported in Table 3. We estimate Equation (4) using industry mean-adjusted measures calculated based on the first and second levels of the GICS industry classifications. Our results remained qualitatively unchanged. We also estimated Equation (5) using the dependent and explanatory variables computed using five years of historical data instead of ten years. The results again remained qualitatively unchanged but slightly weaker.

Second, since our regression tests use individual analysts’ forecasts, there remains the possibility that firms with high analyst following and analysts covering a large number of firms may have disproportionate influence in our regression tests. Based on analyst following, for each of the two samples used for estimating Equation (4) and Equation (5), we partition the sample into two subsamples, one containing firms with the highest quartile of analyst following and the other containing the remaining firms. We perform separate regression tests for the two subsamples and the untabulated results reveal that the main inferences from our tabulated findings also hold for both subsamples. We next partition each of our samples into two subsamples based on analyst firm coverage. One subsample contains observations issued by 
analysts with the highest quartile of firm coverage and the other contains observations issued by the remaining analysts. We conduct regressions for the subsamples and find that the untabulated results reveal that the main inferences from our tabulated findings also hold for both subsamples. We also partitioned samples using the medians of analyst following and analyst coverage and find consistent results. To summarize, we find no evidence to indicate that the results of our study are driven by firms with high analyst following or by analysts who cover a particularly large number of firms.

Finally, we estimated Equation (4) and Equation (5) for a subsample that consists of firms in consumer discretionary, consumer staples, and industrials sectors. Previous studies find that analysts use the $\mathrm{P} / \mathrm{E}$ multiple valuation method to value firms in those sectors. Thus, the measurement errors in the proxies for analyst target E/P multiples, $\frac{E P S_{1}}{\hat{P}_{t+1}}$, should be minimal for this subsample, since dividing the EPS 1 by target price forecast should provide an accurate estimate of the E/P multiple applied by the analyst. The results (untabulated) based on the subsample are consistent with those reported in panel A of Table 3 and Table 4. This suggests that the potential impact of measurement errors in $\frac{E P S_{1}}{\hat{P}_{t+1}}$ on our findings appears to be limited.

\section{Summary and conclusions}

Prior literature has shown that analysts frequently use earnings-based multiples to value firms. The present study uses a rigorous empirical approach based on valuation theory and evidence in broker reports to examine closely the target P/E multiples that analysts apply in equity valuations in order to derive a roadmap of how the multiples are actually arrived at. Our results indicate that, contrary to assumptions of textbook authors and many researchers, analysts employ at least three different benchmarks (comparable firms' forward P/E multiples, firms' historical market 
forward P/E multiples and the market index’s P/E multiples) to help determine magnitudes of P/E multiples for target firms. These are benefits that present value models do not offer.

The findings reported in this study have important implications for anyone interested in analysts' valuation practices and multiples-based valuation methods. Despite its characterization as being simple and lacking theoretical support, our results suggest that analysts' P/E multiplesbased valuation technique is based on the careful examination of expected future payoffs and fundamental analysis. GD observed over sixty years ago that analysts tend to place significant emphasis on near-term earnings that are easier to forecast but less important and useful for valuation purposes. Our findings suggest that not much has changed in this regard in the intervening years. ${ }^{19}$

In addition, the evidence presented here suggests that a potentially refined method of performing earnings multiples-based valuation involves: 1) choosing comparable firms within the industry in which the target firm operates (e.g., based on the third-level GICS codes) and then selecting a P/E multiple for the target firm based on comparisons of its growth in future earnings, expected riskiness, and other fundamentals, with those of comparable firms, and 2) examining the firm’s historical P/E multiples to determine historical norms and making modifications based on the firm's fundamentals. Finally, the choice of a specific multiple must be made without relying on a definite formula or simple decision rules; instead, the choice requires informed judgments of the analyst/investor (Graham and Dodd 1951).

\footnotetext{
${ }^{19}$ The accuracy of analysts' long-term growth forecasts is weaker compared with their near-term forecasts due to factors such as greater uncertainty associated with longer forecast horizons and significant optimism in long-term growth forecasts (e.g., Bradshaw et al. 2012). However, valuation theory suggests that it is critical for analysts to forecast long run future earnings. Moreover, existing evidence suggests that the market appears to reward analysts' efforts to forecast firms' long-term performance and such efforts also improve the performance of analysts' stock recommendations (Jung, et al. 2012, Peasnell et al. 2016).
} 


\section{References}

Alford, A., 1992. Research reports: the effect of the set of comparable firms on the accuracy of the price-earnings valuation method. Journal of Accounting Research 30 (1), 94-107.

Barker, R.G., 1999a. The role of dividends in valuation models used by analysts and fund managers. European Accounting Review 8 (2), 195-218.

Barker, R.G., 1999b. Survey and market-based evidence of industry-dependence in analysts’ preferences between the dividend yield and price-earnings ratio valuation models. Journal of Business Finance and Accounting 26 (3/4), 393-418.

Barker, R. and Imam, S., 2008. Analysts' perceptions of 'earnings quality'. Accounting and Business Research 38 (4), 313-329.

Beaver, W. and Morse, D., 1978. What determines price-earnings ratios? Financial Analysts Journal 34 (4), 65-76.

Bhojraj, S. and Lee, C., 2002. Who is my peer? A valuation-based approach to the selection of comparable firms. Journal of Accounting Research 40 (2), 407-439.

Block, S.B., 1999. A study of analysts: practice and theory. Financial Analysts Journal 55 (4), 86-95.

Boni, L. and Womack, K.L., 2006. Analysts, industries, and price momentum. Journal of Financial and Quantitative Analysis 41 (1), 85-109.

Bradshaw, M. T., 2004. How do analysts use their earnings forecasts in generating stock recommendations? Accounting Review 79 (1), 25-50.

Bradshaw, M. T. and Sloan, R., 2002. GAAP versus the street: an empirical assessment of two alternative definitions of earnings. Journal of Accounting Research 40 (1), 41-66.

Bradshaw, M. T., Drake, M. S., Myers, J. N., and Myers, L. A., 2012. A re-examination of analysts' superiority over time-series forecasts of annual earnings. Review of Accounting Studies 17 (4), 944-968.

Campbell, J. Y. and R. J. Shiller, 1988. Stock prices, earnings, and expected dividends. Journal of Finance 43 (3), 661-676.

Cascino, S., Clatworthy, M., Garcia Osma, B., Gassen, J., Imam, S., and Jeanjean, T., 2014. Who uses financial reports and for what purpose? Evidence from capital providers. Accounting in Europe 11 (2), 189-205.

Demirakos, E.G., Strong, N., and Walker, M., 2004. What valuation models do analysts use? Accounting Horizons 18 (4), 221-240. 
Dudney, D., Jirasakuldech, B., and Zorn T., 2008. Return predictability and the P/E ratio: reading the entrails. Journal of Investing 17 (3), 75-82.

Fama, E.F. and French, K.R., 2000. Forecasting profitability and earnings. Journal of Business 73 (2), 161-175.

Freeman, R. N., Ohlson, J.A., and S.H. Penman, 1982. Book rate-of-return and prediction of earnings changes: An empirical investigation. Journal of Accounting Research 20 (2), 639653.

Gordon, M.J. and Shapiro, E., 1956. Capital equipment analysis: The required rate of profit. Management Science 3(1), 102-110.

Graham, B. and Dodd, D.L., 1951. Security Analysis. $3^{\text {rd }}$ ed. New York, NY: McGraw-Hill.

Hsu, J.C., Kudoh, H., and Yamada, T., 2013. When sell-side analysts meet high-volatility stocks: an alternative explanation for the low-volatility puzzle. Journal of Investment Management 11 (2), 28-46.

Imam, S., Barker, R. and Clubb, C., 2008. The use of valuation models by UK investment analysts. European Accounting Review 17 (3), 503-535.

Jung, B., Shane, P. and Yang, Y.S., 2012. Do financial analysts’ long-term growth forecasts matter? Evidence from stock recommendations and career outcomes. Journal of Accounting and Economics 53(1-2 ), 55-76.

Litzenberger, R.H. and Rao, C.U., 1971. Estimates of the marginal rate of time preference and average risk aversion of investors in electric utility shares: 1960-66. The Bell Journal of Economics and Management Science 2 (1), 265-277.

Liu, J., Nissim, D. and Thomas, J., 2002. Equity valuation using multiples. Journal of Accounting Research 40 (1), 135-172.

Lui, D., Markov, S., and Tamayo, A., 2007. What makes a stock risky? Evidence from sell-side analysts’ risk ratings. Journal of Accounting Research 45 (3), 629-665.

Lundholm, R. and Sloan, R., 2013. Equity Valuation and Analysis with eVal. $3^{\text {rd }}$ ed. New York, NY: McGraw-Hill.

Miller, M. and Modigliani, F., 1961. Dividend policy, growth and value of shares. Journal of Business 34 (4), 411-433.

Morgan Stanley, 2007. Homebuilding Monthly Relative Valuation Chartbook. (January 3).

Morgan Stanley, 2012. Mid \& Large Cap Banks. How Expensive (or Cheap) is Your Bank? (an industry review report, dated June 1, 2012). 
Nissim, D., 2013. Relative valuation of U.S. insurance companies. Review of Accounting Studies 18 (2), 324-359.

Nissim, D. and S.F. Penman, 2001. Ratio analysis and equity valuation: from research to practice. Review of Accounting Studies 6 (1), 109-154.

Ohlson, J.A. and Juettner-Nauroth, B., 2005. Expected EPS and EPS growth as determinants of value. Review of Accounting Studies 10 (2-3), 349-365.

Palepu, K.G., and Healy, P.M., 2013. Business Analysis and Valuation. $5^{\text {th }}$ ed. Mason, Ohio: South-Western.

Peasnell, K. and Yin, Y., 2014. How analysts make stock recommendations and take account of risk in doing so. American Accounting Association Annual Meeting conference paper.

Peasnell, K., Yin, Y., and Lubberink, M., 2016. Analysts’ stock recommendations, earnings growth and risk. Accounting and Finance, forthcoming

Penman, S.H., 2013. Financial Statement Analysis and Security Valuation. $5^{\text {th }}$ ed. New York, NY: McGraw-Hill.

Petersen, M.A., 2009. Estimating standard errors in finance and panel data sets: comparing approaches. Review of Financial Studies 22 (1), 435-480.

Reilly, F.K., Griggs, F.T., and Wong, W., 1983. Determinants of the aggregate stock market earnings multiple. Journal of Portfolio Management 1 (1), 36-45.

Richardson, S., Teoh, S.H., and Wysocki, P.D., 2004. The walk-down to beatable analyst forecasts: the role of equity issuance and insider trading incentives. Contemporary Accounting Research 21 (4), 885-924.

Stigler, G.J., 1963. Capital and Rates of Return in Manufacturing Industries. Princeton, NJ: Princeton University Press.

White, B., 2000. What P/E will the US stock market support? Financial Analysts Journal 56 (6), 30-38.

Yin, Y., Peasnell, K., Lubberink, M. and Hunt, H.G., 2014. Determinants of analysts' target P/E multiples. Journal of Investing 23 (3), 35-42.

Zarowin, P., 1990. What determines earnings-price ratios: revisited. Journal of Accounting, Auditing and Finance 5 (3), 439-457. 
Table 1 Descriptive statistics

\begin{tabular}{|c|c|c|c|c|c|c|c|c|}
\hline Variable & Mean & Std & Min & Q1 & Median & Q3 & Max & $\mathrm{N}$ \\
\hline$\frac{E P S_{1}}{\hat{P}_{t+1}}$ & 0.052 & 0.026 & 0.004 & 0.034 & 0.049 & 0.066 & 0.159 & 147,847 \\
\hline$L T G$ & 0.163 & 0.108 & -0.129 & 0.100 & 0.150 & 0.200 & 0.760 & 157,898 \\
\hline$G_{2}$ & 0.262 & 0.419 & -0.458 & 0.097 & 0.163 & 0.277 & 4.167 & 147,843 \\
\hline LEV & 0.518 & 0.231 & 0.076 & 0.336 & 0.512 & 0.680 & 1.116 & 131,895 \\
\hline VOL & 0.436 & 0.201 & 0.138 & 0.289 & 0.393 & 0.536 & 1.232 & 139,580 \\
\hline$B M$ & 0.440 & 0.295 & -0.072 & 0.230 & 0.374 & 0.579 & 1.753 & 129,816 \\
\hline Size & 7.977 & 1.625 & 4.315 & 6.768 & 7.877 & 9.157 & 12.019 & 130,142 \\
\hline Beta & 1.259 & 0.815 & -0.256 & 0.685 & 1.116 & 1.666 & 4.507 & 139,358 \\
\hline$D Y$ & 0.005 & 0.027 & -0.212 & 0.000 & 0.000 & 0.000 & 3.069 & 139,455 \\
\hline GM & 0.460 & 0.224 & 0.029 & 0.281 & 0.432 & 0.637 & 0.947 & 132,164 \\
\hline$A G_{\text {sales }}$ & 0.139 & 0.132 & -0.140 & 0.049 & 0.114 & 0.204 & 0.732 & 114,444 \\
\hline Earn $_{\text {vol }}$ & 0.054 & 0.073 & 0.001 & 0.014 & 0.029 & 0.062 & 0.589 & 124,539 \\
\hline
\end{tabular}

Panel B: Percentage analyst E/P premium and industry mean-adjusted measures of the variables

\begin{tabular}{|c|c|c|c|c|c|c|c|c|}
\hline Variable & Mean & Std & Min & Q1 & Median & Q3 & Max & $\mathrm{N}$ \\
\hline$\left(\frac{E P S_{1}}{\hat{P}_{t+1}}\right)^{\text {premium }}$ & 0.004 & 0.281 & -0.813 & -0.172 & -0.006 & 0.162 & 1.691 & 47,716 \\
\hline$L T G^{\text {ind_adj }}$ & -0.002 & 0.383 & -1.410 & -0.211 & -0.016 & 0.174 & 1.736 & 47,454 \\
\hline$G_{2}^{\text {ind_adj }}$ & -0.001 & 0.850 & -4.027 & -0.424 & -0.086 & 0.305 & 4.454 & 45,668 \\
\hline$L E V^{\text {ind_adj }}$ & -0.004 & 0.271 & -0.669 & -0.169 & -0.002 & 0.147 & 0.849 & 47,719 \\
\hline$V O L^{\text {ind_adj }}$ & -0.002 & 0.185 & -0.408 & -0.133 & -0.016 & 0.112 & 0.590 & 47,719 \\
\hline$B M^{\text {ind_adj }}$ & -0.007 & 0.408 & -0.857 & -0.301 & -0.043 & 0.242 & 1.287 & 47,720 \\
\hline Size $e^{\text {ind_adj }}$ & 0.001 & 0.122 & -0.300 & -0.083 & -0.001 & 0.081 & 0.339 & 47,718 \\
\hline Beta ${ }_{\text {ind_adj }}$ & -0.003 & 0.371 & -1.096 & -0.237 & -0.026 & 0.204 & 1.401 & 47,621 \\
\hline$D Y^{\text {ind_adj }}$ & -0.053 & 0.666 & -1.000 & 0.000 & 0.000 & 0.000 & 3.789 & 48,206 \\
\hline$G M^{\text {ind_adj }}$ & -0.003 & 0.253 & -0.722 & -0.145 & -0.005 & 0.129 & 0.901 & 46,963 \\
\hline$A G_{\text {sales }}$ ind_adj & 0.001 & 0.823 & -3.594 & -0.441 & -0.041 & 0.399 & 3.794 & 41,857 \\
\hline Earn $_{\text {vol }}$ ind_adj & -0.020 & 0.608 & -0.902 & -0.484 & -0.146 & 0.312 & 2.282 & 45,707 \\
\hline
\end{tabular}


Table 1 (Continued)

Panel C: Deviations of the variables from their long-run averages

\begin{tabular}{|c|c|c|c|c|c|c|c|c|}
\hline Variable & Mean & Std & Min & Q1 & Median & Q3 & Max & $\mathrm{N}$ \\
\hline$\left(\frac{E P S_{1}}{\hat{P}_{t+1}}\right)^{\text {Dev_HisAvg }}$ & 0.012 & 0.019 & -0.040 & -0.001 & 0.010 & 0.022 & 0.073 & 40,148 \\
\hline$L T G^{\text {Dev_HisAvg }}$ & -0.017 & 0.057 & -0.186 & -0.047 & -0.016 & 0.009 & 0.244 & 40,182 \\
\hline$G_{2}^{\text {Dev_HisAvg }}$ & -0.049 & 0.202 & -1.569 & -0.090 & -0.025 & 0.023 & 0.847 & 40,164 \\
\hline$L E V^{\text {Dev_HisAvg }}$ & 0.005 & 0.076 & -0.197 & -0.041 & -0.002 & 0.044 & 0.262 & 40,252 \\
\hline$V O L^{\text {Dev_HisAvg }}$ & -0.059 & 0.164 & -0.502 & -0.154 & -0.075 & 0.024 & 0.546 & 40,444 \\
\hline$B M^{\text {Dev_HisAvg }}$ & 0.032 & 0.144 & -0.382 & -0.056 & 0.022 & 0.105 & 0.571 & 40,242 \\
\hline Size $e^{\text {Dev_HisAvg }}$ & 0.408 & 0.478 & -0.768 & 0.072 & 0.374 & 0.703 & 1.875 & 39,651 \\
\hline Beta Dev_HisAvg & -0.037 & 0.468 & -1.436 & -0.345 & -0.021 & 0.283 & 1.280 & 40,433 \\
\hline$D Y^{\text {Dev_HisAvg }}$ & -0.006 & 0.012 & -0.047 & -0.012 & -0.002 & 0.000 & 0.028 & 39,910 \\
\hline$G M^{\text {Dev_HisAvg }}$ & 0.013 & 0.050 & -0.124 & -0.015 & 0.007 & 0.034 & 0.204 & 39,990 \\
\hline$A G_{\text {sales }}$ Dev_HisAvg & -0.038 & 0.074 & -0.305 & -0.081 & -0.033 & 0.009 & 0.172 & 40,358 \\
\hline Earn $_{\text {vol }}$ Dev_HisAv؟ & -0.002 & 0.020 & -0.099 & -0.009 & -0.001 & 0.006 & 0.076 & 38,232 \\
\hline
\end{tabular}

Panel A reports the descriptive statistics for the levels of variables. Panel B reports the statistics of the industry meanadjusted variables, including percentage E/P multiple premium, growth premium, and excess riskiness of the firm relative to comparable firms, and industry mean-adjusted gross margin ratio, actual five-year sales growth rate, and earnings volatility. Panel C reports the statistics of the measures of the deviations of the variables from their historical averages.

Variable Definitions:

For the following, EPS 1 denotes analyst one-year-ahead earnings per share forecast, $P_{t}$ denotes the current price reported by CRSP, and $\hat{P}_{t+1}$ denotes the analyst target price forecast, which is the analyst's projection of the stock's price, typically at the end of a twelve-month forecast horizon.

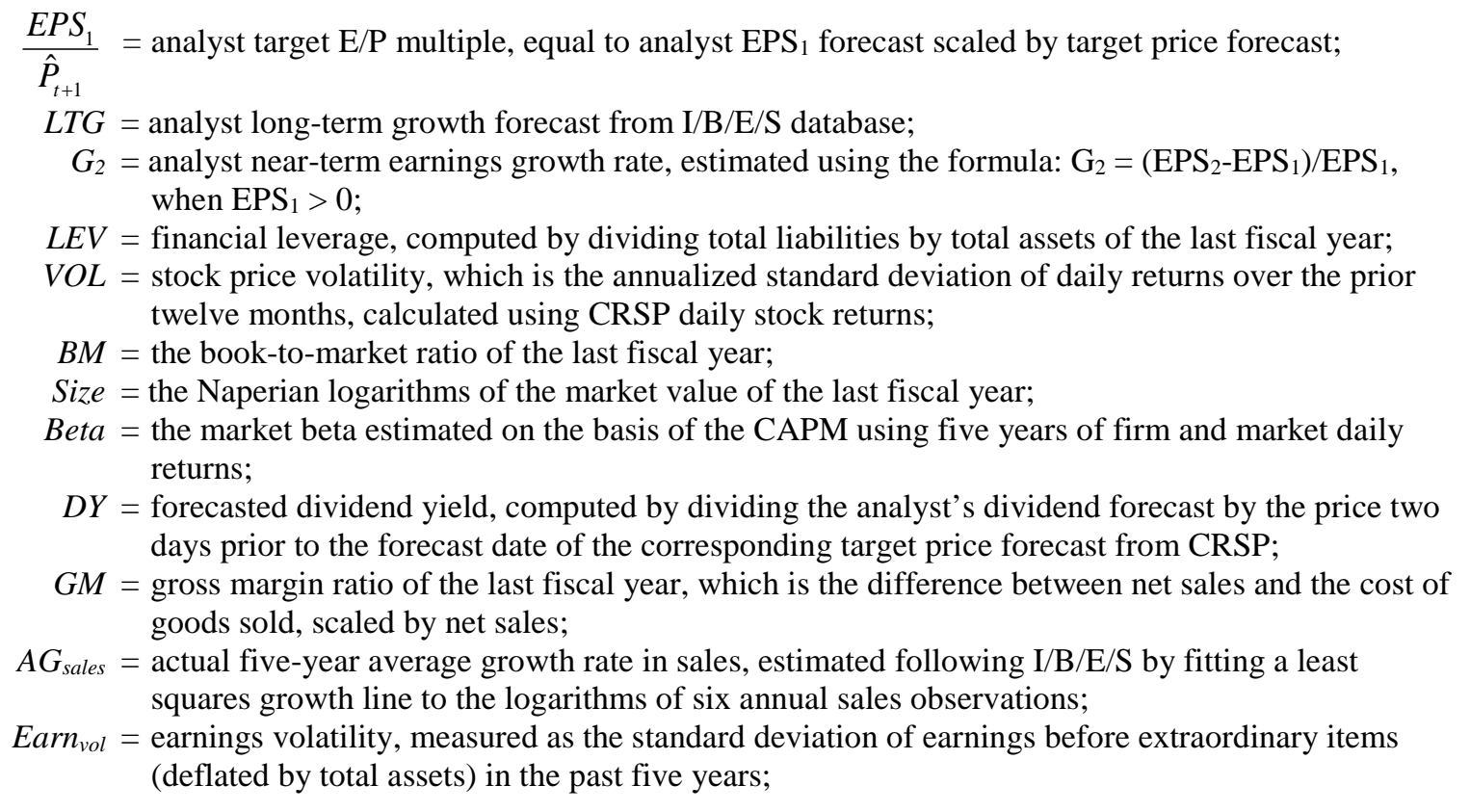




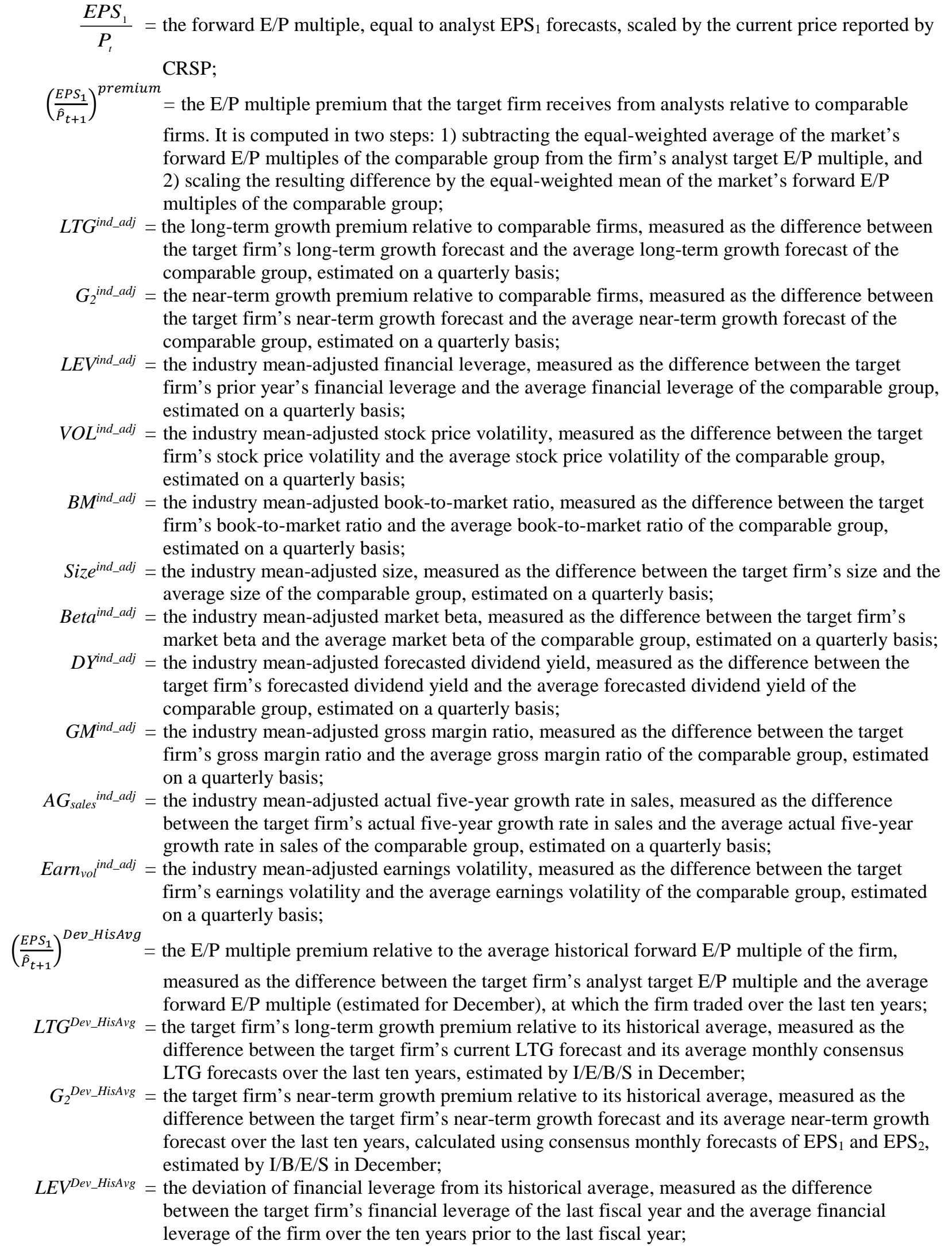


$B M^{\text {Dev_HisAvg }}=$ the deviation of book-to-market from its historical average, measured as the difference between the target firm's book-to-market ratio of the last fiscal year and the average book-to-market ratio of the firm over the ten years prior to the last fiscal year;

Size ${ }^{\text {Dev_HisAvg }}=$ the deviation of size from its historical average, measured as the difference between the Naperian logarithms of the market value of the last fiscal year and the average Naperian logarithms of the market value of the firm in the ten years prior to the last fiscal year;

$D Y^{\text {Dev } \_ \text {HisAvg }}=$ the deviation of forecasted dividend yield from the average historical dividend yield of the firm, measured as the difference between forecasted dividend yield and the average historical dividend yield of the firm over the last ten years;

$G M^{\text {Dev_HisAvg }}=$ the deviation of gross margin ratio from its historical average, measured as the difference between the gross margin ratio of the last fiscal year and the average gross margin ratio of the firm over the ten years prior to the last fiscal year;

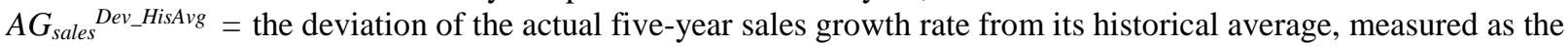
difference between the actual five-year sales growth rate estimated for the last fiscal year, and the average value of the variable estimated over the ten years prior to the last fiscal year;

$E{ } n_{v o l}{ }^{\text {Dev_HisAvg }}=$ the deviation of earnings volatility from its historical average, measured as the difference between earnings volatility estimated for the last fiscal year, and the average value of the variable estimated over the ten years prior to the last fiscal year. 
Table 2 Correlation analysis

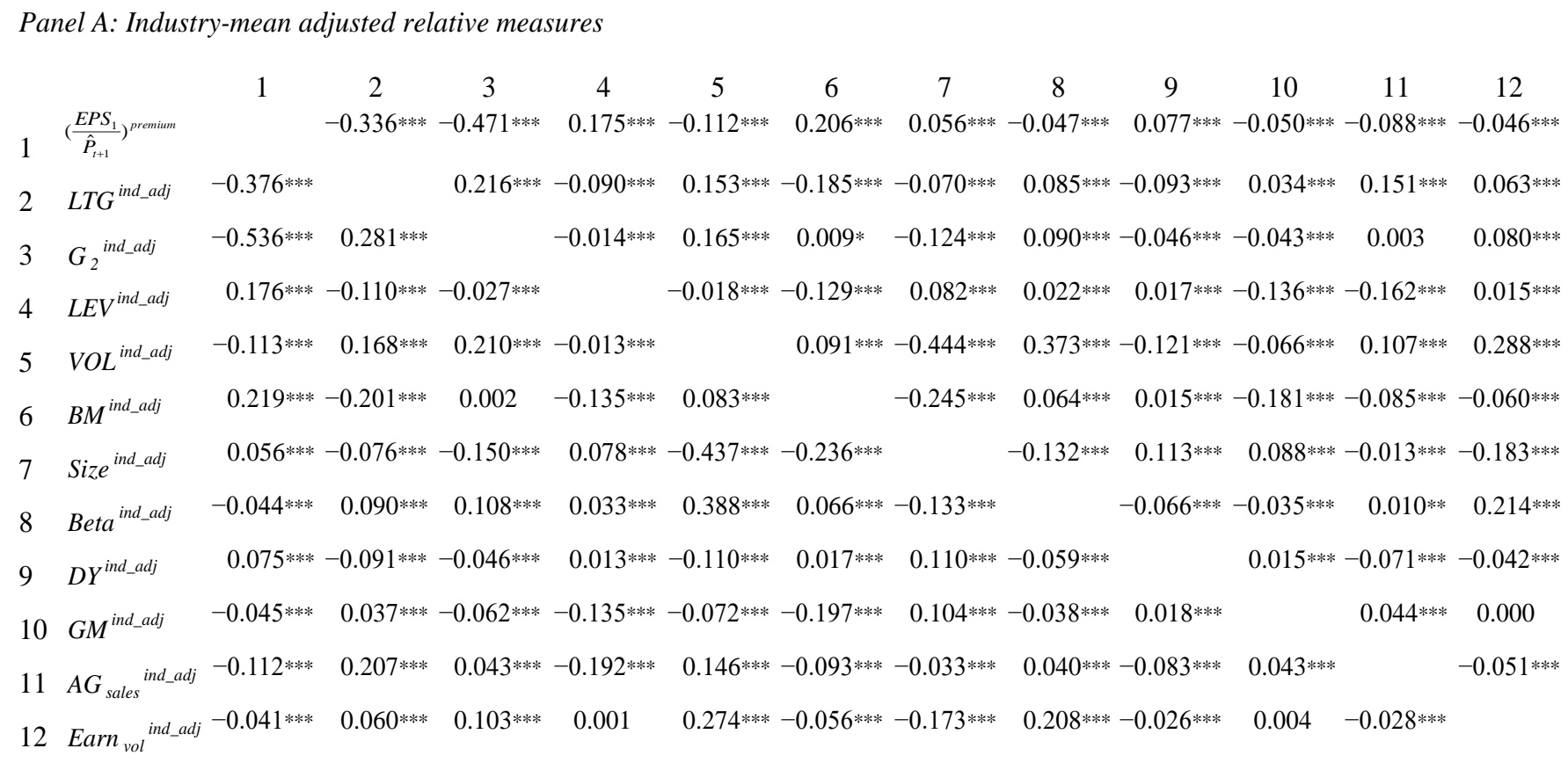

Panel B: Deviations of the variables from their historical averages

\begin{tabular}{|c|c|c|c|c|c|c|c|c|c|c|c|c|c|}
\hline & & 1 & 2 & 3 & 4 & 5 & 6 & 7 & 8 & 9 & 10 & 11 & 12 \\
\hline & $\left(\frac{E P S_{1}}{\hat{n}}\right)^{D e v \_H i s A v g}$ & & $-0.125^{\star \star \star}$ & $-0.323^{\star \star \star ~}$ & -0.005 & $0.085^{\star \star \star}$ & $-0.036^{\star \star \star}$ & $0.144^{\star \star \star}$ & $-0.122^{\star \star \star}$ & 0.002 & $0.116^{\star \star \star}$ & 0.130 *** & * $-0.021^{\text {*** }}$ \\
\hline & $\begin{array}{l}P_{t+1} \\
L T G^{\text {Dev_HisAvg }}\end{array}$ & $-0.125^{\star \star \star}$ & & $0.114^{\star \star *}$ & 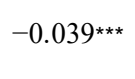 & $0.052^{\star \star \star}$ & $-0.223^{\star \star \star}$ & $0.139 * * \star$ & $0.054 * \star \star$ & $-0.118^{\star \star \star}$ & 0.005 & $0.135^{\star \star \star}$ & $0.026^{\star \star \star}$ \\
\hline & $G_{2}^{\text {Dev_HisAvg }}$ & $-0.328^{\star \star \star}$ & 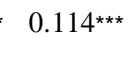 & & $0.022^{\star \star \star}$ & $0.043^{\star \star \star}$ & 0.037 *** & $-0.085^{\star \star \star *}$ & $0.023^{\star \star \star}$ & $-0.035^{\star \star \star}$ & 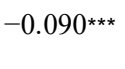 & 0.002 & -0.004 \\
\hline & $L E V^{\text {Dev_HisAvg }}$ & -0.005 & -0.039 *** & 0.022 *** & & $0.052 \star \star \star$ & $-0.050^{\star \star \star}$ & $-0.275^{\star \star \star *}$ & $-0.043^{\star \star \star}$ & $0.009 *$ & 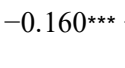 & & * 0.007 \\
\hline & $V O L^{\text {Dev_HisAvg }}$ & $0.085^{\star \star \star *}$ & * 0.052 *** & $0.043^{\star \star *}$ & $0.052^{\star \star *}$ & & $0.062^{\star \star *}$ & -0.091 *** & $0.142^{\star \star \star ~}$ & $-0.158^{\star \star \star}$ & -0.101 *** & $0.192^{\star \star \star}$ & 0.119 *** \\
\hline & $B M^{\text {Dev_HisAvg }}$ & $-0.036^{\star \star \star}$ & -0.223 *** & $0.037 * \star \star$ & 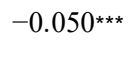 & $0.062^{\star \star \star}$ & & $-0.515^{\star * \star}$ & 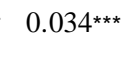 & $0.085^{\star \star *}$ & -0.159 *** & $-0.096^{\star \star \star *}$ & $\star-0.014$ *** \\
\hline & $S i z e^{D e v \_H i s A v g}$ & $0.144 \star \star \star *$ & * $0.139 * \star \star$ & 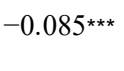 & $-0.275^{\star \star \star}$ & $-0.091 \star \star \star$ & $-0.515^{\star \star \star}$ & & $-0.098^{\star \star *}$ & $0.068^{\star \star \star}$ & $0.244 * \star \star$ & $0.116 * \star \star$ & * -0.043 *** \\
\hline & Beta ${ }^{\text {Dev_HisAvg }}$ & 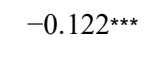 & 0.054 *** & 0.023 *** & -0.043 *** & 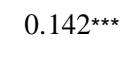 & 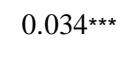 & -0.098 *** & & $-0.021 \star \star \star *$ & $-0.041^{\star \star \star *}$ & -0.009 * & * 0.170 *** \\
\hline & $D Y^{\text {Dev_HisAvg }}$ & 0.002 & $-0.118^{\star \star \star}$ & $-0.035^{\star \star \star *}$ & $0.009 * \star \star$ & $-0.158^{\star \star \star}$ & 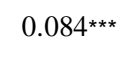 & $0.068^{\star \star \star *}$ & -0.021 *** & & $0.009^{*}$ & ${ }^{*}-0.161^{\star \star * *}$ & * -0.080 *** \\
\hline & $G M^{\text {Dev_HisAvg }}$ & $0.116^{\star \star \star}$ & 0.005 & $-0.090^{\star \star \star}$ & $-0.160^{\star \star \star *}$ & $-0.101^{\star \star \star}$ & $-0.159^{\star \star \star *}$ & $0.244^{\star \star \star *}$ & $-0.041^{\star \star \star}$ & $0.009^{*}$ & & $-0.021^{\text {*** }}$ & * 0.006 \\
\hline & $A G_{\text {sales }}^{\text {Dev_HisAvg }}$ & 0.130 *** & $0.135^{\star \star \star}$ & 0.002 & $-0.062^{\star \star \star}$ & $0.192^{\star \star *}$ & $-0.096^{\star \star \star}$ & $0.116^{\star \star \star *}$ & -0.009 * & $-0.161^{\star \star \star}$ & $-0.021^{\star \star *}$ & & 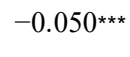 \\
\hline & Earn $_{v o l}$ Dev_HisAvg & -0.021 *** & 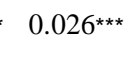 & -0.004 & 0.007 & $0.119 * \star \star$ & $-0.014 \star \star \star *$ & $-0.043^{\star \star *}$ & $0.170^{\star \star \star \star}$ & 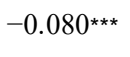 & 0.006 & 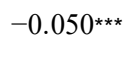 & \\
\hline
\end{tabular}

*, **, *** Indicate significance at the 10 per cent, 5 per cent, and 1 per cent levels, respectively, in two-tailed tests. The table shows both the Spearman correlations (lower left) and the Pearson correlations (upper right) of variables used in our empirical analysis. Panel A shows the correlations of the industry mean-adjusted relative measures of the variables. Panel B shows the correlations of the deviations of the variables from their historical averages. All variables are as previously defined in Table 1. 
Table 3 Results of tests of Hypotheses 1 and 1a

$$
\begin{aligned}
\left(\frac{E P S_{1, i t}}{\hat{P}_{t+1, i t}}\right)^{\text {premium }} & =\alpha+\beta_{1} L T G_{i t}^{\text {ind_adj }}+\beta_{2} G_{2, i t}^{\text {ind_adj }}+\beta_{3} L E V_{i t}^{\text {ind_adj }}+\beta_{4} V O L_{i t}^{\text {ind_adj }}+\beta_{5} S i z e_{i t}^{\text {ind_adj }}+\beta_{6} B M_{i t}^{\text {ind_adj }} \\
& +\beta_{7} \text { Beta }_{i t}^{\text {ind_adj }}+\beta_{8} D Y_{i t}^{\text {ind_adj }}+\beta_{9} G M_{i t}^{\text {ind_adj }}+\beta_{10} A G_{\text {sales,it_ }}^{\text {ind_adj }}+\beta_{11} E_{\text {Ern }}^{\text {ind_adj }}+\varepsilon_{\text {vol, it }}
\end{aligned}
$$

\begin{tabular}{|c|c|c|c|c|c|c|c|c|c|c|c|}
\hline Model & Pred. sign & $\underline{1}$ & & $\underline{\mathbf{2}}$ & $\underline{\mathbf{3}}$ & & $\underline{4}$ & & $\underline{\mathbf{5}}$ & & $\underline{6}$ \\
\hline \multirow[t]{2}{*}{ Intercept } & $?$ & 0.003 & & 0.001 & 0.001 & & 0.004 & * & 0.004 & & $0.004 * *$ \\
\hline & & $(1.25)$ & & $(0.23)$ & $(0.25)$ & & (1.63) & & $(1.48)$ & & $(2.02)$ \\
\hline \multirow[t]{2}{*}{$L T G^{\text {ind_adj }}$} & - & -0.255 & $* * *$ & & -0.191 & $* * *$ & -0.144 & $* * *$ & -0.187 & $* * *$ & $-0.141 * * *$ \\
\hline & & $(-37.69)$ & & & $(-32.32)$ & & $(-26.70)$ & & $(-28.88)$ & & $(-23.25)$ \\
\hline \multirow[t]{2}{*}{$G_{2}^{\text {ind_adj }}$} & - & & & $-0.162 * * *$ & -0.144 & $* * *$ & -0.145 & $* * *$ & -0.149 & $* * *$ & $-0.150 * * *$ \\
\hline & & & & $(-56.88)$ & $(-54.31)$ & & $(-54.28)$ & & $(-51.43)$ & & $(-48.76)$ \\
\hline \multirow[t]{2}{*}{$L E V^{\text {ind_adj }}$} & + & & & & & & 0.188 & $* * *$ & & & $0.184^{* * *}$ \\
\hline & & & & & & & (23.29) & & & & (20.53) \\
\hline \multirow[t]{2}{*}{$V O L^{\text {ind_adj }}$} & + & & & & & & -0.038 & $* * *$ & & & $-0.043 * * *$ \\
\hline & & & & & & & $(-2.97)$ & & & & $(-2.95)$ \\
\hline \multirow[t]{2}{*}{$B M^{\text {ind_adj }}$} & + & & & & & & 0.141 & $* * *$ & & & $0.138 * * *$ \\
\hline & & & & & & & (24.31) & & & & (20.48) \\
\hline \multirow[t]{2}{*}{ Size $e^{\text {ind_adj }}$} & - & & & & & & 0.045 & $* *$ & & & $0.052 * *$ \\
\hline & & & & & & & $(2.27)$ & & & & $(2.33)$ \\
\hline \multirow[t]{2}{*}{ Beta ${ }^{\text {ind_adj }}$} & $?$ & & & & & & -0.001 & & & & 0.007 \\
\hline & & & & & & & $(-0.21)$ & & & & (1.15) \\
\hline \multirow[t]{2}{*}{$D Y^{i n d \_a d j}$} & + & & & & & & 0.015 & $* * *$ & & & $0.014 * * *$ \\
\hline & & & & & & & (6.07) & & & & $(4.85)$ \\
\hline \multirow[t]{2}{*}{$G M^{\text {ind_adj }}$} & - & & & & & & & & -0.073 & $* * *$ & -0.011 \\
\hline & & & & & & & & & $(-8.16)$ & & $(-1.16)$ \\
\hline \multirow[t]{2}{*}{$A G_{\text {sales }}$ ind_adj } & - & & & & & & & & -0.019 & $* * *$ & -0.004 \\
\hline & & & & & & & & & $(-7.29)$ & & $(-1.52)$ \\
\hline \multirow[t]{2}{*}{ Earn $_{\text {vol }}^{\text {ind_adj }}$} & + & & & & & & & & -0.002 & & $0.011^{* * *}$ \\
\hline & & & & & & & & & $(-0.55)$ & & $(2.71)$ \\
\hline $\mathrm{n}$ & & 39,428 & & 39,428 & 39,428 & & 39,428 & & 35,300 & & 32,028 \\
\hline Adj. $\mathrm{R}^{2}$ & & $12 \%$ & & $22 \%$ & $29 \%$ & & $35 \%$ & & $29 \%$ & & $35 \%$ \\
\hline
\end{tabular}


Table 3 (Continued)

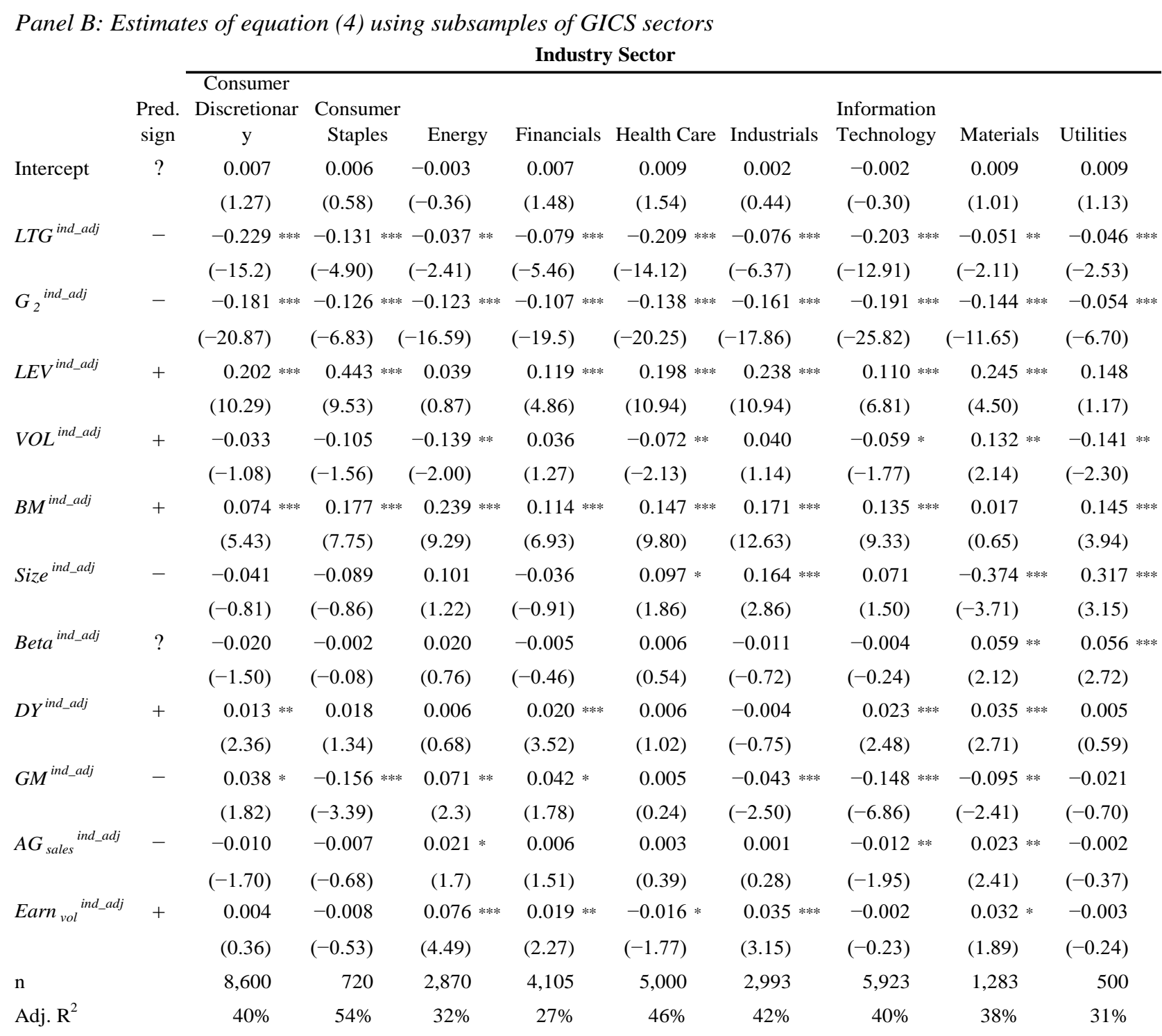

$*, * *, * * *$ Indicate that the coefficient estimate differs from zero at p-values of $<0.10,<0.05,<0.01$, respectively, in two-tailed tests. t-statistics are shown in parentheses. This table reports the estimates of Equation (4). Panel A reports results for the pooled sample. Panel B reports the results for each GICS sector. $\left(\frac{E P S_{1, i t}}{\hat{P}_{t+1, i t}}\right)^{\text {premium }}$ represents firm i's E/P multiple premium assigned at date $t ; L T G_{i t_{-}}^{\text {indadj }}$ and $G_{2, i t}^{\text {ind adj }}$ are two relative growth premiums forecasted at date $t ; L E V_{i t}^{\text {ind_adj }}$, Size in _adj,$B M_{i t}^{\text {ind_adj }}$ and $G M_{i t}^{\text {ind_adj }}$ represent industry mean-adjusted risk measures and gross margin ratio, calculated using the variable levels at the beginning of the $\mathrm{EPS}_{1}$ forecast period; $D Y_{i t}^{\text {ind _adj }}$ represents the industry mean-adjusted forecasted dividend yield, calculated based on the dividend forecast issued at date $t$ and price at date $t ; V_{i t}^{\text {ind } \_a d j}$ and $B_{\text {Beta }}^{\text {ind } \_a d j}$ represent, respectively, industry mean-adjusted historical 12-month

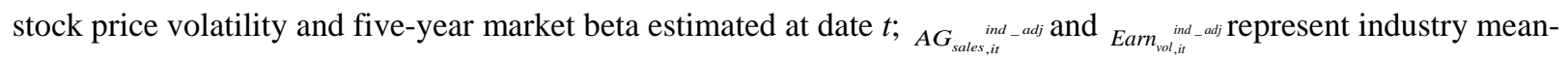
adjusted sales growth rate and earnings volatility in the last five years, respectively. 
Table 4 Results of tests of Hypothesis 2

$$
\begin{aligned}
\left(\frac{E P S_{1, i t}}{\hat{P}_{t+1, i t}}\right)^{\text {Dev_HisAvg }}= & \alpha+\beta_{1} L T G_{i t}^{\text {Dev_HisAvg }}+\beta_{2} G_{2, i t}^{\text {Dev_HisAvg }}+\beta_{3} L E V_{i t}^{\text {Dev_HisAvg }}+\beta_{4} V O L_{i t}^{\text {Dev_HisAvg }} \\
& +\beta_{5} \text { Size }_{i t}^{\text {Dev_HisAvg }}+\beta_{6} B M_{i t}^{\text {Dev_HisAvg }}+\beta_{7} \text { Beta }_{i t}^{\text {Dev_HisAvg }}+\beta_{8} \text { DY }_{i t}^{\text {Dev_HisAvg }} \\
& +\beta_{9} G M_{i t}^{\text {Dev_HisAvg }}+\beta_{10} A G_{\text {sales, it }}^{\text {DevisAvg }}+\beta_{11} \text { Earn }_{\text {vol, it }}^{\text {DevHisAvg }}+\varepsilon_{i t}
\end{aligned}
$$

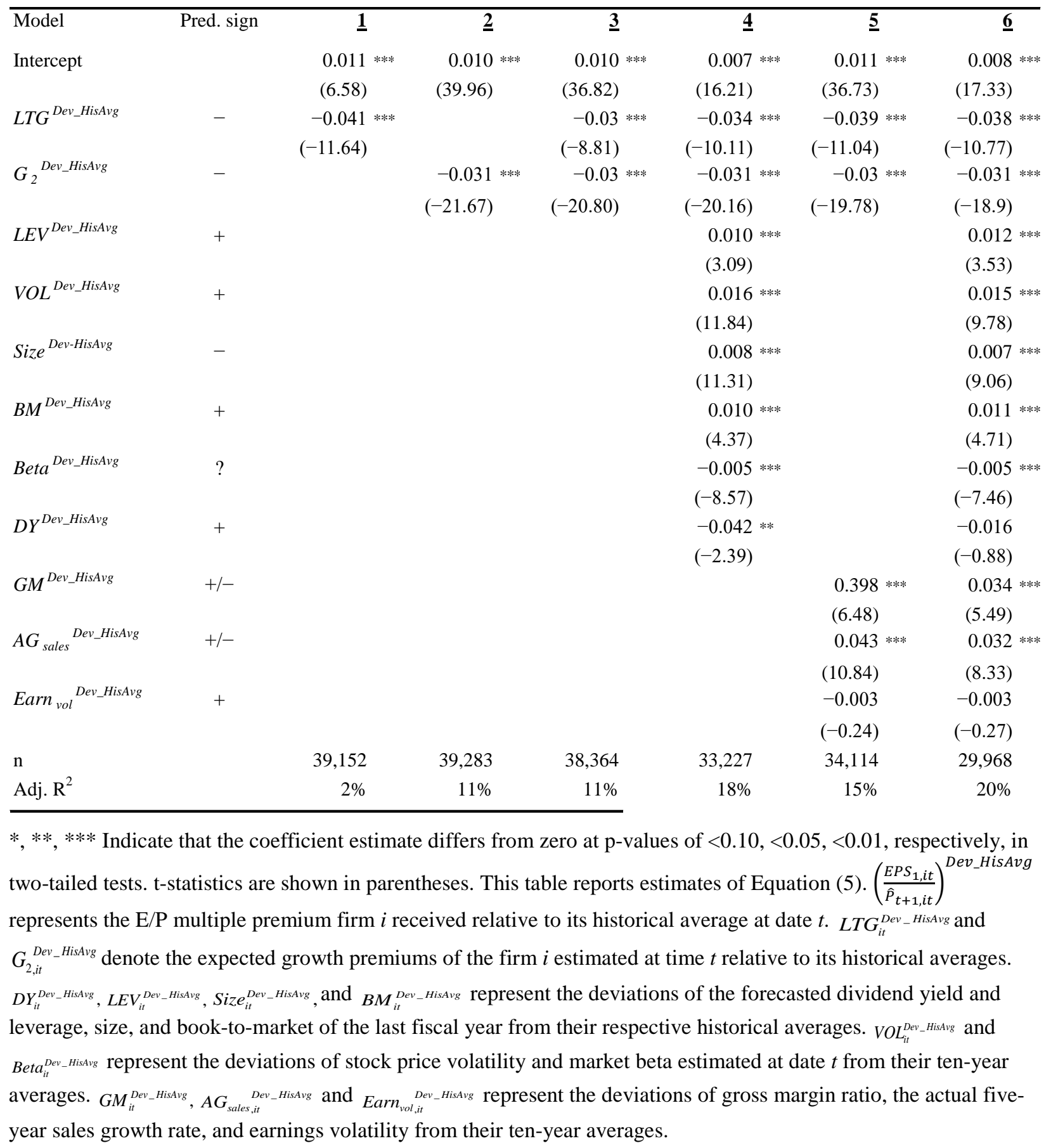


Table 5 Changes in the market index E/P multiples and analyst target E/P multiples

$$
\Delta\left(\frac{\text { EPS }_{1, i t}}{\hat{P}_{t+1, i t}}\right)=\alpha+\beta_{1} \Delta S P 500 E P_{t}+\text { Control } \text { Variables }_{i t}+\varepsilon_{i t}
$$

\begin{tabular}{|c|c|c|c|c|}
\hline Model & Pred. sign & $\underline{1}$ & $\underline{2}$ & $\underline{3}$ \\
\hline Intercept & $?$ & $\begin{array}{l}0.000 * * * \\
(2.80)\end{array}$ & $\begin{array}{l}0.000 * * * \\
(9.14)\end{array}$ & $\begin{array}{l}0.000 * * * \\
(3.05)\end{array}$ \\
\hline$\triangle S P 500 E P$ & + & $\begin{array}{l}0.423 * * * \\
(12.07)\end{array}$ & $\begin{array}{l}0.383 \text { *** } \\
(50.01)\end{array}$ & $\begin{array}{l}0.353 * * * \\
(38.71)\end{array}$ \\
\hline$\Delta L T G$ & - & & $\begin{array}{l}-0.023 \text { *** } \\
(-17.37)\end{array}$ & $\begin{array}{l}-0.019 * * * \\
(-11.72)\end{array}$ \\
\hline$\Delta G_{2}$ & - & & $\begin{array}{l}-0.024 * * * \\
(-90.27)\end{array}$ & $\begin{array}{l}-0.025 \text { *** } \\
(-67.92)\end{array}$ \\
\hline$\triangle L E V$ & + & & & $\begin{array}{l}0.009 * * * \\
(5.46)\end{array}$ \\
\hline$\triangle V O L$ & + & & & $\begin{array}{l}0.016 \text { *** } \\
(19.35)\end{array}$ \\
\hline$\triangle B M$ & + & & & $\begin{array}{l}0.008 \text { *** } \\
(7.01)\end{array}$ \\
\hline$\Delta$ Size & - & & & $\begin{array}{l}0.004 * * * \\
(9.90)\end{array}$ \\
\hline$\Delta$ Beta & $?$ & & & $\begin{array}{l}0.001 \text { *** } \\
(3.46)\end{array}$ \\
\hline$\Delta D Y$ & + & & & $\begin{array}{l}0.164 \text { *** } \\
(10.82)\end{array}$ \\
\hline$\Delta G M$ & - & & & $\begin{array}{l}0.010 * * * \\
(2.72)\end{array}$ \\
\hline$\Delta A G_{\text {sales }}$ & - & & & $\begin{array}{l}-0.004 * * \\
(-1.96)\end{array}$ \\
\hline$\Delta$ Earn $_{\text {vol }}$ & + & & & $\begin{array}{l}-0.006 \\
(-1.11)\end{array}$ \\
\hline $\mathrm{n}$ & & 87,327 & 82,458 & 51,921 \\
\hline Adj. $\mathrm{R}^{2}$ & & $5 \%$ & $25 \%$ & $26 \%$ \\
\hline
\end{tabular}

$*, * *, * * *$ Indicate that the coefficient estimate differs from zero at p-values of $<0.10,<0.05,<0.01$, respectively, in two-tailed tests. t-statistics are shown in parentheses. This table reports the estimates of Equation (6) to examine the relation between changes in the S\&P 500 Index forward E/P multiple and changes in analysts' target $\mathrm{E} / \mathrm{P}$ multiples. $\triangle E P S_{1, i t} / \widehat{P}_{t+1, i t}$ represents the change in firm $i$ 's target $\mathrm{E} / \mathrm{P}$ multiple. $\triangle S P 500 E P_{t}$ represents the change in the forward E/P multiple for the S\&P 500 Index in date $t$ calendar month. $\triangle L T G_{i t}$ and $\Delta G_{2, i t}$ represent changes in the two growth forecasts. $\triangle L E V_{i t}, \triangle V O L_{i t}$, $\triangle B M_{i t}, \Delta \log M V_{i t}$ and $\triangle B e t a_{i t}$ represent, respectively, changes in financial leverage, stock price volatility, book-to-market, size, and market beta. $\triangle D Y_{i t}$ represents the change of the dividend yield. $\Delta G M_{\text {it }}, \Delta A G_{\text {sales,it }}, \Delta E a r n_{v o l, i t}$ represent changes in gross margin ratio, sales growth rate and earnings volatility in the past five years. 